\title{
Interacting Business Cycle Fluctuations: A Two Country Model
}

\author{
Carl Chiarella \\ School of Finance and Economics \\ University of Technology, Sydney \\ Australia
}

\author{
Peter Flaschel \\ Faculty of Economics \\ University of Bielefeld \\ Germany
}

\author{
Hing Hung \\ School of Finance and Economics \\ University of Technology, Sydney \\ Australia
}

January 4, 2006

\begin{abstract}
In this paper we develop a model of business cycle fluctuations between two interacting open economies within the disequilibrium or non-market clearing paradigm. We analyze the main feedback mechanisms (Keynes, Mundell, Rose and Dornbusch) driving the dynamics and the conflict between their stabilizing and destabilizing tendencies and how these depend on certain key speeds of adjustment in the real and foreign exchange sectors. We explore numerically a variety of situations of interacting price cycles in the two countries, where the steady state is locally repelling, but where the overall dynamics are bounded in an economically meaningful domain by assuming downward money wage rigidity.
\end{abstract}

Keywords: International business cycles, stability, instability, persistence, coupled oscillators.

JEL Classification: E12, E32.

Acknowledgement: The authors are indebted to an anonymous referee whose insightful and detailed comments have led to a vastly improved final version of this paper. The usual caveat applies. 


\section{Introduction}

Economists have long been concerned with understanding the causes of the seemingly regular fluctuations in aggregate economic quantities, more usually known as the business cycle. The extensive research on this topic has both an empirical and a theoretical dimension. The empirical research has focused on various statistical features and stylized facts of observed business cycles, refining considerably the early measures of Burns and Mitchell (1946); in this regard see for example Harding and Pagan (2002) and references contained therein. The focus of theoretical developments has been to seek a better understanding of the underlying economic mechanisms driving the business cycle. One may loosely categorize these developments into two broad camps. One approach has a distinctly microeconomic focus with a utility maximizing representative agent intertemporally optimizing in reaction to external shocks. It would be fair to state that the way in which the stochastic processes for the external shocks are modelled plays an important role in the dynamic behavior of these models. Real business cycle theory is of course the prominent, currently very much in vogue, example of this type of modelling and Cooley (1995) probably still provides the best overview. The other approach focuses on the macroeconomic aggregates themselves and models their interaction as dynamic adjustment processes in a disequilibrium or non-market clearing framework. According to this view business fluctuations come about when economic conditions are such that the destabilizing feedback chains dominate. For an exposition of this approach one may consult Dore (1993) and Chiarella and Flaschel (2000).

As far as international business cycles are concerned interest amongst economists has been equally intense, especially in recent decades with the liberalization of exchange rate regimes, the resulting increase in international capital flows and the increasing globalization of world trade. In addition to the issues concerning closed economies, empirical research here has also focused on the co-movement of macro-economic aggregates across countries; see for example Gregory, Head and Raynauld (1997) and Baxter and Stockman (1989) . The two broad approaches referred to above have been extended by theoretical modelling to the two (or multi-) country situation. A good example of the real business cycle approach can be found in Canova and Marrinan (1998), whilst Asada et al (2003) discuss the disequilibrium approach.

The empirical literature on the international business cycle has brought out a number of important stylized facts. In discussing the international business cycle from the perspective of real business cycle theory Backus, Kehoe and Kydland (1995) identify as one of the important stylized facts the high variability of the terms of trade. Koopman and Valle e Azevedo (2003) highlight the issue of the synchronization of international business cycles.

In this paper we contribute to the disequilibrium literature with a model that focuses on the co-movement of prices and the terms of trade ${ }^{1}$, developed by extending to a two country world the integrated disequilibrium macro-modelling of Chiarella and Flaschel (2000). This framework allows analysis of international business cycles and of basic economic feedback chains; specifically, the interactions of stabilizing and destabilizing dynamic economic

\footnotetext{
${ }^{1}$ Brenner, Weidlich and Witt(2002) also develop a model that focuses on co-movements of business cycles. Their model may also be viewed as a disequilibrium model, but its set-up is very different from the model we develop here.
} 
processes. There are four basic feedback mechanisms ${ }^{2}$ identified in that framework namely; the Rose real wage effect (involving the positive or negative feedback effect of real wages on their rate of change) which may be stabilizing or destabilizing; the Keynes real rate of interest effect (the channel from prices to the nominal interest rate) which is generally stabilizing; the Mundell real rate of interest effect (this essentially focuses on the positive feedback from the expected rate of inflation on its own time rate of change) which is more likely to be destabilizing; the Metzler inventory effect (the interaction of flexible adjustment of inventories with adjustment of sales expectations) which may be stabilizing or destabilizing. The closed economy business cycles that are generated in this framework arise from the interaction between these feedback mechanisms when the destabilizing tendencies become predominant, usually on account of certain speeds of adjustment moving into regions where the model dynamics are locally unstable. Our two country framework in this paper assumes that the first three of these mechanisms exist in each country, and in addition the two countries are linked via the Dornbusch capital gains accelerator effect (arising from exchange rate flexibility and capital mobility increasing, possibly without bound, the influence of the expected change in exchange rates on the actual exchange rate change) that is destabilizing in general.

A two country model consistently integrating all of these elements, in particular by taking careful account of budget restrictions, is laid out in Asada et al. (2003). It results in a system of differential equations for 14 state variables and is labelled the KMG (KeynesMetzler-Goodwin) model. These dynamic equations are highly interlinked and turn out to be difficult to analyze analytically. A simplified version of the KMG approach can be obtained by assuming that Metzlerian quantity adjustment does not take place. Thus firms always operate at full capacity level and the role of aggregate goods demand here is to directly explain (rather than by a detour through Metzlerian quantity adjustment) the rate of inflation on the basis of its deviation from full capacity level.

The resulting model framework is labelled the KWG (Keynes-Wicksell-Goodwin) approach. Its characteristic is that it provides a short-cut to a theory of price inflation by assuming that inflation, and not sales expectations, is directly driven by excess demand in the market for goods with firms always producing at full capacity level. The technical advantage of the KWG approach is that it reduces by two the number of dynamic equations for each country, thus leaving us with a system of differential equations for 10 state variables. Whilst large by some standards it turns out to be possible to undertake local stability analysis of this system. Ignoring Metzlerian quantity adjustments may seem like throwing out the baby with the bathwater as far as a discussion of international business cycles is concerned. However our aim here is to focus on the mechanisms driving (or preventing) co-movement of goods prices and the terms of trade. Our simulations of the model reveal business cycle co-movements with different features from previous work in this area. In particular, we find that with all four feedback chains operating adverse phase synchronization of prices may readily arise. We also find that persistent fluctuations in prices (again with adverse phase synchronization) and terms of trade may arise as the speed of exchange rate adjustment increases. Other findings include the transmission of persistent economic fluctuations between countries due to changes in steady state inflation policy and the different impact on phase synchronization of prices under fixed and flexible exchange rate regimes.

\footnotetext{
${ }^{2}$ to be discussed in detail in the body of the paper.
} 
The plan of the paper is as follows. In section 2 we outline the structure of the two interacting KWG economies. Of necessity this consists of many equations, but our exposition will highlight the main feedback chains and the conflict between the stabilizing and destabilizing tendencies. Section 3 lists a number of assumptions we make in order to reduce the model to a manageable form, lays out the equations of the model in intensive form, and discusses the steady state and some propositions concerning transition from local stability to local instability. Section 4 gives some numerical simulations of the model illustrating a number of phenomena such as the international transmission of price movements, the variability in the terms of trade, the different impact of fixed and floating exchange rate systems on international business cycle synchronization, and the effect of different monetary growth rate policies in each country. Section 5 concludes.

\section{Two Interacting KWG Economies}

This section sets up the KWG approach in the case of two large open economies interacting with each other through trade in goods as well as financial assets and the resulting net interest flows. ${ }^{3}$ We shall use linear equations to model behavioral relationships as far as is possible, in order to have a model with only intrinsic nonlinearities as a starting point of our investigations. However in order to obtain bounded dynamics we do introduce one extrinsic nonlinearity, namely the wage-kink, as discussed in section 4. A broad study of extrinsic nonlinearities based, for example, on downward wage rigidity, on intertemporal constraints, on market dependent adjustment parameters and on bounded import functions is left to future research.

\subsection{The basic modules}

We choose the units such that domestic expressions are in terms of the domestic good or the domestic currency, and foreign country expressions in terms of the commodity produced by the foreign country (or - if nominal - in the foreign currency), unless otherwise specified. An asterisk indicates a foreign country variable, while a subscript ' 2 ' on a variable indicates that the variable is sourced from the other country. We use the superscript + to denote forward-looking variables, to be explained when they first occur. The notation used to describe the basic modules is laid out in the notation index. Since both countries are modelled analogously we will focus on the domestic economy in the following presentation of the components of the model. The description and justification of the equations presented in the various modules of the model will be brief, since many of the structural equations of closed economy KWG dynamics are already well-documented and explained in Chiarella and Flaschel (2000, ch.3). The corresponding two country dynamics are symmetrical.

1. Definitions (remunerations, wealth, real exchange rate):

The first module of the model defines the real wage, $\omega$, the actual rate of profit, $\rho$ and real wealth, $W$. The latter consists of real money balances, equities, bonds issued by

\footnotetext{
${ }^{3}$ Since the allocation and accumulation of domestic and foreign bonds are not completely specified, the KWG approach to two-country monetary macrodynamics remains a partial description of a two-country world.
} 
the domestic government $B_{1}$ and bonds issued by the foreign government $B_{2}$. These bonds have a constant price, normalized to one, and a variable interest rate, $r$ and $r^{*}$, respectively. Since adding the possibility of holding foreign equities as well does not affect the main features of the model, we restrict ourselves to bonds as the only foreign asset domestic residents can hold. Thus,

$$
\begin{aligned}
\omega & =w / p, \quad \rho=\left(Y-\delta K-\omega L^{d}\right) / K \\
W & =\left(M+B_{1}+e B_{2}+p_{e} E\right) / p, \quad p_{b}=p_{b^{*}}=1 .
\end{aligned}
$$

There will be two corresponding equations for $w^{*}$ and $W^{*}$, the foreign real wage and wealth. The real exchange rate

$$
\eta=p /\left(e p^{*}\right), \quad[\text { Goods* } / \text { Goods }]
$$

describes the exchange ratio between foreign and domestic goods. It is the inverse of the quantity referred to as the terms of trade.

2. Households - workers and asset-holders:

We assume two groups of households that differ with respect to their savings behavior - workers who do not save; and asset holders who have a constant average propensity to save, $s_{c}$, out of their disposable income. Furthermore, both groups spend a fraction $\left(1-\gamma_{w}\right.$ and $1-\gamma_{c}$, respectively) of their consumption expenditures on imports, $C_{2}$. We assume that $\gamma_{w}$ is constant, while the fraction $\gamma_{c}$ is a negative function of the real exchange rate $\eta$, indicating that asset holders shift their consumption expenditures in favor of the commodity that becomes relatively cheaper. The disposable income of asset holders, $Y_{c}^{D}$ consists of profits, interest payments from domestic bonds and interest payments from foreign bonds - all net of taxes (which are paid in the country from where this interest income originates). We assume that the tax rate on wage income is zero. Furthermore, the asset holders decide how to split up their wealth between the different assets (a superscript $d$ indicates demand). Here we assume that domestic bonds and domestic equities are perfect substitutes, which implies an equation for the price of equities. The stock demand for real money balances depends on output, $Y$ (reflecting the transaction motive), on wealth and the nominal interest rate. Equation (9) indicates that the asset holders have to hold their intended savings in the four assets that are available to them. Finally, we assume that the labor force $L$ grows at a constant exogenous rate $n$. The situation of the households in the domestic economy is thus given by 


$$
\begin{aligned}
W & =\left(M^{d}+B_{1}^{d}+e B_{2}^{d}+p_{e} E^{d}\right) / p \\
M^{d} & =h_{1} p Y+h_{2} p W\left(1-\tau_{c}\right)\left(r_{o}-r\right) \\
Y_{c}^{D} & =\left(1-\tau_{c}\right)\left(\rho K+r B_{1} / p\right)+e\left(1-\tau_{c}^{*}\right) r^{*} B_{2} / p \\
C_{1} & =\gamma_{w} \omega L^{d}+\gamma_{c}(\eta)\left(1-s_{c}\right) Y_{c}^{D}, \gamma_{w}, \gamma_{c}(\eta) \in[0,1], \\
C_{2} & =\eta\left(\left(1-\gamma_{w}\right) \omega L^{d}+\left(1-\gamma_{c}(\eta)\right)\left(1-s_{c}\right) Y_{c}^{D}\right), \\
S_{p} & =\omega L^{d}+Y_{c}^{D}-C=s_{c} Y_{c}^{D}=\left(\dot{M}^{d}+\dot{B}_{1}^{d}+e \dot{B}_{2}^{d}+p_{e} \dot{E}^{d}\right) / p \\
C & =C_{1}+C_{2} / \eta, \\
\hat{L} & =n=\text { constant, }
\end{aligned}
$$

There will be a corresponding set of equations for the foreign country quantities $W^{*}, M^{d *}, Y_{c}^{D *}, C_{2}^{*}, C_{1}^{*}, S_{p}^{*}, C^{*}$ and $\hat{L}^{*}$.

3. Firms (production-units and investors):

Output of firms is produced via the two factors, labor and capital, using a technology with fixed input coefficients. Capital is always fully utilized whereas demand for labor, $L^{d}$, may differ from the total work force, $L$. The investment per unit of capital depends on the difference between the profit rate and the real interest rate and $n$ as a trend component. Equation (15) defines the excess supply, $Y^{e x s}$, on the domestic goods market. Since we have assumed that firms' factor payments, (in the form of wages and profits, i.e. there are no retained earnings), always amount to $Y$, they have to finance $Y^{e x s}$ as well as their intended investment by issuing equities. This is indicated in (16) where actual investment, $I^{a}$, is defined as the sum of intended and involuntary investment. Intended investment will be the only factor affecting the capital stock since all unsold production results in a change in the stock of inventories, as indicated by equation (18). This stock increases [decreases] if actual output exceeds [falls short of] aggregate demand. Moreover, a positive $\delta_{2}$ reflects the assumption that firms try to hold the stock of inventories proportional to output. Because of our assumption concerning the production technology this implies a constant ratio of inventories and capital stock in the steady state. Our assumptions on firm behavior imply that the savings of firms are always identically zero. Thus the firms can be described by the set of equations:

$$
\begin{aligned}
Y & =y K, L^{d}=Y / x, y, x=\text { constant } \\
V & =L^{d} / L, \\
I & =i(\rho-(r-\pi)) K+n K, \\
Y^{e x s} & =Y-\delta K-C_{1}-C_{1}^{*}-I-G, \\
p_{e} \dot{E} / p & =I+Y^{e x s}=I^{a} \quad\left(S_{f}=0\right), \\
\hat{K} & =I / K \\
\dot{N} & =\delta_{2} K+Y^{\text {exs }}
\end{aligned}
$$

There will be a corresponding set of equations for the foreign country quantities $Y^{*}$, $I^{*}, Y^{* e x s}, p_{e}^{*} \dot{E}^{*} / p^{*}, \hat{K}^{*}$ and $\dot{N}^{*}$. 
4. Government (fiscal and monetary authority):

This module describes the role of government in the economy. In equation (19) it levies a tax (at constant tax rate $\tau_{c}$ ) on profits and on interest payments from domestic bonds, i.e. only the asset holders pay taxes. Note that the interest payments going to foreigners who hold domestic bonds are also taxed. Equation (20) characterizes government expenditures as being a constant fraction of the capital stock $K$, so simplifying steady state analysis. Equation (21) defines government savings as fiscal receipts net of interest payments minus government spending. Equation (22) expresses the assumption that the central bank of the home country keeps the domestic money supply on a growth path with an exogenous rate, $\mu$. Consistent with this assumption, the government budget constraint then states in (23) that the time rate of change of the supply of government bonds (that in fact reaches the public) is determined by two items; the negative of government savings (the government deficit that must be financed) minus that part of the new money supply that is injected into the economy via open market operations (which reduces the supply of new government bonds) and not via the foreign exchange market. ${ }^{4}$ The equations describing government behavior are:

$$
\begin{aligned}
T & =\tau_{c}(\rho K+r B / p), \quad B=B_{1}+B_{1}^{*}, \\
G & =g K, g=\text { const. } \\
S_{g} & =T-r B / p-G \\
\hat{M} & =\dot{M} / M=\mu \\
\dot{B} & =p G+r B-p T-\dot{M},
\end{aligned}
$$

A similar set of equations holds for the foreign country government with respect to the quantities $T^{*}, G^{*}, S_{g}^{*}, \hat{M}^{*}$ and $\dot{B}^{*}$.

5. Equilibrium conditions and consistency requirements (asset-markets):

With regard to the asset markets we assume continuous market clearing at the end of each 'trading day' (ex post). Equation (24) indicates the respective stock equilibria for the three domestic assets. Note that the demand for domestic bonds stems from domestic as well as from foreign asset owners. Equation (26) directly follows from the assumption that domestic bonds and equities are perfect substitutes. Hence, the rate of interest net of taxes, $\left(1-\tau_{c}\right) r$, has to be equal to the actual rate of return on equities. This rate can be calculated as follows. In each period, all expected profits, $\rho p K$, are paid out to equity holders. Taking the tax and perfectly foreseen untaxed capital gains into account, the rate of return on equities, therefore, amounts to $\left(1-\tau_{c}\right) \rho p K / p_{e} E+\hat{p}_{e}$. Equation (27) then characterizes the respective flow equilibria. We assume that the government and the firms face no demand problems when issuing new bonds or equities, respectively. Note that the division of new bonds between domestic and

\footnotetext{
${ }^{4}$ We do not consider foreign market operations by the central banks.
} 
foreign asset holders is ambiguous. ${ }^{5}$ Once their flow demands fulfill the condition $\dot{B}=\dot{B}_{1}^{d}+\dot{B}_{1}^{d *}$, however, these demands are realized $\left(\dot{B}_{1}=\dot{B}_{1}^{d}\right.$ and $\left.\dot{B}_{1}^{*}=\dot{B}_{1}^{d *}\right)$. The equilibria in the asset markets are thus given by:

$$
\begin{aligned}
M & =M^{d}=h_{1} p Y+h_{2} p W\left(1-\tau_{c}\right)\left(r_{o}-r\right), \\
B & =B_{1}^{d}+B_{1}^{d *} \\
E & =E^{d} \\
\left(1-\tau_{c}\right) r & =\frac{\left(1-\tau_{c}\right) \rho p K}{p_{e} E}+\hat{p}_{e}, \\
\dot{M} & =\dot{M}^{d}, \dot{B}=\dot{B}_{1}^{d}+\dot{B}_{1}^{d *}, \dot{E}=\dot{E}^{d},
\end{aligned}
$$

There will be a corresponding set of equations for $M^{*}, B^{*}, p_{e}^{*} E^{*}$ and $\dot{M}^{*}$, from the foreign country asset market.

6. Disequilibrium situation (goods-markets):

In this module, the first two equations describe the disequilibrium situations on the market for the domestic and the foreign good, respectively. Then, as (30) shows, aggregate savings (which consist of private and public savings) equal the sum of actual investment and net private capital exports $\left(\left(e \dot{B}_{2}-\dot{B}_{1}^{*}\right) / p\right)$. The whole expression is equal (due to our assumptions on income, consumption and the allocation of savings) to actual investment, plus net exports of goods, and plus the excess of foreign interest payments to domestic residents holding foreign bonds over domestic interest payments to foreigners holding home-country bonds (both net of taxes). ${ }^{6}$ This is a direct implication of the fact that the surpluses in all accounts of the balance of payments have to sum up to zero. See also below where we explain the balance of payments in greater detail. Naturally, as shown in (32), for the world as a whole, aggregate

\footnotetext{
${ }^{5}$ For $\dot{M}=\dot{M}^{d}, \dot{E}=\dot{E}^{d}, \dot{M}^{*}=\dot{M}^{d *}, \dot{E}^{*}=\dot{E}^{d *}$, equations (9), (27) and the corresponding foreign country equations lead to

$$
\left[\begin{array}{cccc}
1 & e & 0 & 0 \\
0 & 0 & 1 / e & 1 \\
1 & 0 & 1 & 0 \\
0 & 1 & 0 & 1
\end{array}\right]\left[\begin{array}{c}
\dot{B}_{1}^{d} \\
\dot{B}_{2}^{d} \\
\dot{B}_{1}^{d *} \\
\dot{B}_{2}^{d *}
\end{array}\right]=\left[\begin{array}{c}
p S_{g}-\dot{M}-p_{e} \dot{E} \\
p^{*} S_{g}^{*}-\dot{M}^{*}-p_{e}^{*} \dot{E}^{*} \\
\dot{B} \\
\dot{B}^{*}
\end{array}\right]
$$

for the four unknowns $\dot{B}_{1}^{d}, \dot{B}_{2}^{d}, \dot{B}_{1}^{d *}$ and $\dot{B}_{2}^{d *}$. The rank of the $4 \times 4$ matrix on the left hand side is three, yielding one degree of freedom. Hence, once the division of new domestic bonds between domestic residents and foreigners is chosen the division of foreign bonds is also determined.

${ }^{6}$ Whereas (30) follows directly from inserting the use of private and government savings from (9) and (21), the derivation of (301) is slightly more complicated. Using the definitions of private and government savings, $S=S_{p}+S_{g}=\omega L^{d}+Y_{c}^{D}-C+T-r B / p-G$. Inserting expressions for $Y_{c}^{D}, C$ and $T$ according to (6), (10) and (19) yields $S=\omega L^{d}+\rho K-C_{1}-\left(e p^{*} / p\right) C_{2}-G-r B_{1} / p+e\left(1-\tau_{c}^{*}\right) r^{*} B_{2} / p$. Making use of the definition of $\rho$ in (1) and noting that from (15) and (16) that $Y-\delta K-G-C_{1}=Y^{e x s}+I+C_{1}^{*}=I^{a}+C_{1}^{*}$, one finally obtains the desired expression.
} 
savings equal aggregate actual investment.

$$
\begin{aligned}
Y & \neq C_{1}+C_{1}^{*}+I+\delta K+G\left[Y^{e x s} \neq 0\right], \\
Y^{*} & \neq C_{2}^{*}+C_{2}+I^{*}+\delta^{*} K^{*}+G^{*}\left[Y^{* e x s} \neq 0\right], \\
S & =S_{p}+S_{g}=I^{a}+\left(e \dot{B}_{2}-\dot{B}_{1}^{*}\right) / p \\
& =I^{a}+\left\{C_{1}^{*}-\left(e p^{*} / p\right) C_{2}\right\}+\left\{e\left(1-\tau_{c}^{*}\right) r^{*} B_{2} / p-\left(1-\tau_{c}\right) r B_{1}^{*} / p\right\}, \\
S^{*} & =S_{p}^{*}+S_{g}^{*}=I^{a *}+\left(\dot{B}_{1}^{*} / e-\dot{B}_{2}\right) / p^{*} \\
& =I^{a *}+\left\{C_{2}-\left(p / e p^{*}\right) C_{1}^{*}\right\}+\left\{\left(1-\tau_{c}\right) r B_{1}^{*} /\left(e p^{*}\right)-\left(1-\tau_{c}^{*}\right) r^{*} B_{2} / p^{*}\right\}, \\
S^{w} & =S+\left(e p^{*} / p\right) S^{*}=I^{a}+\left(e p^{*} / p\right) I^{a *}=I^{a w} .
\end{aligned}
$$

7. Wage-Price-Sector (adjustment equations):

This module describes the adjustment of wages, prices, and inflationary expectations. Wage and price inflation are modelled analogously in that both are a combination of demand pressure and cost pressure factors. Wage inflation adjusts with reaction speed $\beta_{w}$ to the deviation of the actual rate of employment from the NAIRU rate of employment. Furthermore, it is influenced by the actual rate of change in the workers' price index, $\hat{p}_{w}$, and the expected future rate of change, $\pi_{w}$. Underlying this formulation is the assumption that not only current but also medium run workers' price inflation is important in the wage bargaining process. From (34), the current rate of workers' price inflation amounts to the weighted sum of domestic price inflation and foreign price inflation (converted into domestic currency), where the weights are the proportions of the respective goods in workers' consumption expenditures. The construction of $\pi_{w}$ is completely analogous, except that only expected magnitudes are used. Note that the use of $\hat{p}$ and $\pi$ in lieu of $\hat{p}_{w}$ and $\pi_{w}$ in equation (33) would imply an exchange rate illusion on the part of workers. According to (36) price inflation, however, adjusts with reaction speed $\beta_{p}$ to the actual excess supply on the goods market as a demand pressure factor and on wage inflation as a cost push force. Furthermore, the expected price trend, $\pi$, influences today's price inflation in a similar way as today's wage inflation. Equation (37) describes the formation of inflationary expectations concerning the medium-run. These react with speed $\beta_{\pi}$ to a term consisting of a backward looking first term (adaptive expectations with weight $\alpha_{\pi}$ ) and a forward looking second term (with weight $1-\alpha_{\pi}$ and characterized by means of a + sign) that refers to some price forecasting method (e.g. the p-star concept of the FED). The wage-price dynamics are thus given by:

$$
\begin{aligned}
\hat{w} & =\beta_{w}(V-\bar{V})+\kappa_{w} \hat{p}_{w}+\left(1-\kappa_{w}\right) \pi_{w}, \\
\hat{p}_{w} & =\gamma_{w} \hat{p}+\left(1-\gamma_{w}\right)\left(\hat{e}+\hat{p}^{*}\right), \quad p_{w}=p^{\gamma_{w}}\left(e p^{*}\right)^{1-\gamma_{w}} \\
\pi_{w} & =\gamma_{w} \pi+\left(1-\gamma_{w}\right)\left(\epsilon+\pi^{*}\right) \\
\hat{p} & =-\beta_{p}\left(Y^{e x s} / K\right)+\kappa_{p} \hat{w}+\left(1-\kappa_{p}\right) \pi \\
\dot{\pi} & =\beta_{\pi}\left(\alpha_{\pi}(\hat{p}-\pi)+\left(1-\alpha_{\pi}\right)\left(\hat{p}^{+}-\pi\right)\right)
\end{aligned}
$$

There will be a corresponding set of equations for the wage-price sector in the foreign country including $\hat{w}^{*}, \hat{p}^{*}, \dot{\pi}^{*}, \hat{p}_{w}^{*}$ and $\pi_{w}^{*}$. 
8. Exchange rate dynamics:

Module 8 describes the dynamics of the exchange rate and the formation of expectations about its rate of change. Equation (38) reflects our assumption that the interest rate differential (augmented by depreciation expectations) in the international bond market determines (via corresponding international capital flows) the way and the extent by which the growth rate of the exchange rate deviates from its steady state value in conjunction with the imbalance that exists in the trade account (per unit of capital). The exchange rate adjusts to these imbalance at the speed $\beta_{e}$. Note also that we allow here for imperfect capital mobility, ${ }^{7}$ which is captured by the parameter $\beta$. Dornbusch type models of the open economy usually assume perfect capital mobility (corresponding to $\beta=\infty$ ) and perfect substitutability of the assets traded internationally. These assumptions are the root cause of the prevalence of the UIP-condition (Uncovered Interest Parity) as the standard theory of the determination of exchange rate dynamics. Our formulation extends this approach and allows for (some) imperfection with respect to capital mobility and exchange rate flexibility. Equation (40) expresses the mechanism by which exchange rate expectations, $\epsilon$, are formed namely by adjusting with speed $\beta_{\epsilon}$ to a factor that is again a weighted average of 'backward' and 'forward' looking components. On the one hand, we use adaptive expectations (as the simplest expression for a chartist type of behavior) and, on the other hand, theory based expectations ${ }^{8}$ (using for example the relative form of the PPP) as a simple description of a fundamentalist type of behavior. We assume here that domestic and foreign asset holders form the same expectations regarding the exchange rate. The equations expressing exchange rate dynamics are:

$$
\begin{aligned}
\hat{e} & =\beta_{e}\left(\beta\left(\left(1-\tau_{c}^{*}\right) r^{*}+\epsilon-\left(1-\tau_{c}\right) r\right)-N X / K\right)+\hat{e}_{o}, \\
\hat{e}_{o} & =\hat{p}_{o}-\hat{p}_{o}^{*}, \\
\dot{\epsilon} & =\beta_{\epsilon}\left(\alpha_{\epsilon}(\hat{e}-\epsilon)+\left(1-\alpha_{\epsilon}\right)\left(\hat{e}^{+}-\epsilon\right)\right) .
\end{aligned}
$$

\section{Balance of Payments:}

The first three equations of this module concern the trade balance and denote exports and imports of goods and also net exports (see also module 2). Equation (44) indicates net interest payments $(N I X)$ from abroad: foreign interest payments to domestic asset holders minus domestic interest payments to foreigners (assumed to be transferred through the foreign exchange market). Another international transaction is the change in the stock of foreign bonds domestic residents hold. NCX denotes net capital exports, i.e. the deficit in the private capital account; the excess of additional foreign bonds held by domestic asset owners over additional domestic bonds held by foreigners. Note that, taking the exchange rate into account, NIX ${ }^{*}$ and $N C X^{*}$ are simply mirror images of the respective domestic magnitudes. In (46), $Z$ denotes the overall surplus in the balance of payments. It consists of the surplus in the current account (first and second bracket), the surplus in the private capital account (third bracket). As stated in (46), $Z$ is identically equal to zero on the basis

\footnotetext{
${ }^{7}$ This is in contrast to the assumption for domestically traded bonds and equities.

${ }^{8}$ For simplicity, only asymptotically rational expectations are assumed here.
} 
of what has been assumed so far. This is the well-known accounting identity, i.e., the magnitudes considered are ex-post equilibrium magnitudes. The same is true for the various terms in (30) - (32) described above, from which it immediately follows that $Z=0$ is indeed fulfilled. Thus we have:

$$
\begin{aligned}
E x= & \left(\left(1-\gamma_{w}^{*}\right) \omega^{*} L^{d *}+\left(1-\gamma_{c}^{*}(\eta)\right)\left(1-s_{c}^{*}\right) Y_{c}^{D *}\right) / \eta=C_{1}^{*}=I m^{*} / \eta, \\
I m= & \left(1-\gamma_{w}\right) \omega L^{d}+\left(1-\gamma_{c}(\eta)\right)\left(1-s_{c}\right) Y_{c}^{D}=C_{2} / \eta=E x^{*} / \eta, \\
N X / p= & E x-I m=-N X^{*} / \eta \\
N I X= & e\left(1-\tau_{c}^{*}\right) r^{*} B_{2}-\left(1-\tau_{c}\right) r B_{1}^{*}=-e N I X^{*}, \\
N C X= & e \dot{B}_{2}^{d}-\dot{B}_{1}^{* d}=-e N C X^{*}, \\
Z= & p N+N I X-N C X \\
= & \left\{p C_{1}^{*}-e p^{*} C_{2}\right\}+\left\{e\left(1-\tau_{c}^{*}\right) r^{*} B_{2}-\left(1-\tau_{c}\right) r B_{1}^{*}\right\} \\
- & \left\{e \dot{B}_{2}^{d}-\dot{B}_{1}^{* d}\right\} \\
= & 0, \\
Z^{*}= & p^{*} N X^{*}+N I X^{*}-N C X^{*} \\
= & \left\{p^{*} C_{2}-p C_{1}^{*} / e\right\}+\left\{\left(1-\tau_{c}\right) r B_{1}^{*} / e-\left(1-\tau_{c}^{*}\right) r^{*} B_{2}\right\} \\
& -\left\{\dot{B}_{1}^{* d} / e-\dot{B}_{2}^{d}\right\} \\
= & -Z / e=0 .
\end{aligned}
$$

\subsection{The feedback channels of the model}

As we discussed briefly in section 1 our two-country model of disequilibrium adjustment has five basic feedback channels. However, as we pointed out, in this paper we shall suppress the Metzlerian inventory channel in order to simplify the interaction between the various feedback channels, this also has the effect of reducing by four the number of differential equations describing the dynamics of the two-country economy. Each of the feedback channels of the model is summarized in Table 1, here we spell out how they operate.

First, the Keynes effect: an increase (decrease) in nominal wages leads to an increase (decrease) in prices via a cost-push effect, this in turn leads to an increase (decrease) in the nominal interest rate via the money market equilibrium condition. This leads to a decrease (increase) in investment, that translates into lower (higher) output and labor demand ${ }^{9}$. All of these effects then feed back into the nominal wage dynamics to lower nominal wages. The effects described here operate when parameters are such that this feedback channel is stabilizing, which it usually is.

Second, the Mundell effect: an increase (decrease) in wage inflation leads to an increase (decrease) in inflation and thus also in expected inflation through the inherent dynamics of the wage price sector. As a consequence the expected real interest rate declines (rises) thus increasing (decreasing) investment. This in turn leads to increasing (decreasing) output and labor demand. Via the demand pressure and cost pressure effects in the wage-price sector,

\footnotetext{
${ }^{9}$ Of course there must be a rise in the real interest rate in order for there to be en effect on real investment. However we remind the reader that the analysis of the individual feedback chain is a ceteris paribus one.
} 
wage inflation and expected inflation both rise (fall) further. A caveat on the Mundell effect would be that the Fisher effect at least partially works against the Mundell feedback. The Fisher effect focuses on the fact that as expected inflation rises, expected real interest rates fall, investment rises, with subsequent demand pressure increases leading to higher prices, this brings about cuts in the real money supply, which in turns leads to a rise in nominal and real interest rates until equilibrium in the goods market is restored via a fall in investment. There would be a tension here between how fast inflation expectations via the Mundell effect are increasing relative to how fast the nominal interest rate was rising via the Fisher effect. However generally we would expect the Mundell effect to dominate and so this feedback channel is destabilizing and thus conflicts with the Keynes effect.

Third, the Rose effect, which can operate either in a positive or adverse way. Consider first the positive Rose effect; real wages rise (decline) leading to a fall (rise) in investment and rise (fall) in consumption, but investment falling (rising) faster than consumption rises (falls). As a result output and labor demand fall (rise) as do nominal wages and prices. The positive Rose effect comes about if nominal wages fall (rise) faster than prices so that the real wage falls (rises) and the feedback channel is stabilizing. Alternatively the adverse Rose effect comes about if prices fall (rise) faster than nominal wages so that the real wage rises (falls) further and thus this feedback channel is destabilizing. The same two effects arise if consumption rises (falls) more quickly than investment falls (rises), as shown in Table 1, with the role of wage and price flexibilities now being inverted.

All of the above mentioned feedback channels operate primarily in the real part of the economy. The Dornbusch capital gains accelerator effect operates solely on the financial part of the economy. An increase (decrease) in the expected rate of change of the exchange rate leads to an increase (decrease) in the expected rate of return on foreign bonds, leading in turn to an increased (decreased) demand for foreign bonds. This in turn leads to an increase (decrease) in the exchange rate, and consequently a further increase (decrease) in the expected rate of change of the exchange rate. This channel is thus destabilizing in general.

The dynamics of the two-country economy are thus driven by four feed-back channels, some of which are stabilizing and some destabilizing. The tendency of the economy to generate self-sustaining fluctuations will depend on the destabilizing forces dominating the stabilizing ones. The parameters that most strongly affect this trade-off are the speeds of adjustment of the various dynamic processes we have to laid out in section 2.1. In section 3 we shall discuss how this trade-off works.

\section{The Core 10D KWG Growth Dynamics}

In this section we lay out the intensive form representation of the two-country KWG growth dynamics (to be simulated in section 4) on the basis of certain assumptions that simplify its structure without sacrificing too much in generality. In particular the accumulation of internationally traded bonds does not feedback into the core 10D-dynamics of the model and so may be neglected. We thus obtain a structure whose local stability that can be easily investigated. 


\begin{tabular}{|c|c|c|}
\hline Name & Feedback Chain & Stability \\
\hline Keynes Effect & $\begin{array}{l}w \uparrow \Rightarrow p \uparrow \Rightarrow r \uparrow \Rightarrow I \downarrow \\
\Rightarrow Y \downarrow \Rightarrow L^{d} \downarrow \Rightarrow w \downarrow\end{array}$ & $\begin{array}{l}\text { generally } \\
\text { stabilizing }\end{array}$ \\
\hline Normal Rose Effects & $\begin{array}{c}\frac{w}{p} \uparrow \Rightarrow I \Downarrow C \uparrow \Rightarrow Y \downarrow L^{d} \downarrow \\
w \Downarrow p \downarrow \Rightarrow \frac{w}{p} \downarrow \\
\text { or } I \downarrow C \Uparrow \text { and } \\
Y, L^{d \uparrow w \uparrow p \Uparrow \frac{w}{p} \downarrow}\end{array}$ & generally stabilizing \\
\hline Adverse Rose Effects & $\begin{array}{c}\frac{w}{p} \uparrow \Rightarrow I \Downarrow C \uparrow \Rightarrow Y \downarrow L^{d} \downarrow \\
\Rightarrow w \downarrow p \Downarrow \Rightarrow \frac{w}{p} \uparrow \\
\text { or } I \downarrow C \Uparrow \text { and } \\
Y, L^{d \uparrow} \uparrow \Uparrow p \uparrow \frac{w}{p} \uparrow\end{array}$ & generally destabilizing \\
\hline Mundell Effect & $\begin{array}{l}\hat{w} \uparrow \Rightarrow \pi \uparrow \Rightarrow \pi^{e} \uparrow r-\pi^{e} \downarrow \\
\Rightarrow I \uparrow \Rightarrow Y, L^{d} \uparrow \Rightarrow \pi \uparrow \hat{w} \uparrow\end{array}$ & $\begin{array}{c}\text { generally } \\
\text { destabilizing }\end{array}$ \\
\hline $\begin{array}{c}\text { Dornbusch } \\
\text { Capital Gains Accelerator }\end{array}$ & $\begin{array}{c}\epsilon \uparrow \Rightarrow \text { Expected Return } \uparrow \Rightarrow \\
B^{* d} \uparrow \Rightarrow \hat{e} \uparrow \Rightarrow \epsilon \uparrow\end{array}$ & $\begin{array}{c}\text { generally } \\
\text { destabilizing }\end{array}$ \\
\hline
\end{tabular}

Table 1: The Main Feedback Channels

\subsection{The intensive form dynamics}

The particular assumptions are the following: ${ }^{10}$

- $W$, in the money demand function, is replaced by $K$ as a narrow definition of domestic wealth (this removes feedback channels from bond and equity accumulation from part of the model).

- $t_{c}=\left(T_{c}-r B_{1} / p-e r_{o}^{*} B_{2} / p\right) / K=$ const., where $T_{c}=\tau_{c}\left(\rho K+r B_{1} / p\right)+\tau_{c}^{*} e r^{*} B_{2} / p$ represents the sum of all taxes paid by domestic asset holders worldwide. This tax collection rule replaces the earlier profit tax collection rule and removes another feedback route from the accumulation of domestic and foreign bonds. ${ }^{11}$

In particular, this assumption will allow us to disregard the $\mathrm{G}$ (overnment)B(udget)R(estraint) and the evolution of worldwide government debt in the following analysis of the model. ${ }^{12}$ In making use of this simplifying device we employ similar assumptions to those of Sargent (1987, ch.V) and Rødseth (2000, ch.6).

- $\gamma_{w} \equiv 1$ : Wage earners consume domestic goods solely (but we still have $\gamma_{c}(\eta)$ depending on the real exchange rate with $\left.\gamma_{c}^{\prime}<0\right)$. This simplifies the wage/price dynamics, which become identical to those of a closed economy.

- $\rho_{o}^{e *}=\rho_{o}^{e}$ : The domestic steady state rate of profit is identical to that of the foreign economy. This allows the interest rate parity condition to coincide with the relative

\footnotetext{
${ }^{10}$ The assumptions we make for the foreign economy are the same as the ones for the domestic economy and are therefore not made explicit in this section.

${ }^{11}$ It remains for future research to investigate how important such feedbacks routes are for the dynamics of the model in general.

${ }^{12}$ The parameter $\tau_{c}$ has thus to be removed from the model's equations, as taxes are now lump-sum.
} 
form of the PPP in the steady state or (equivalently) allows the removal of any trend from the real exchange rate in the steady state.

- $n=n^{*}$ : Yielding a uniform real rate of growth in the world economy in the steady state.

- $\hat{p}^{+}=\hat{p}_{o}=\mu-n$ : The simplest rule for the formation of forward looking expectations of the rate of inflation (see equation 37) by means of the quantity theory of money.

- $\hat{e}^{+}=\hat{e}_{o}=\hat{p}_{o}-\hat{p}_{o}^{*}=\mu-\mu^{*}$ : The simplest rule for the formation of forward looking expectations of the rate of change of the exchange rate (see equation 40 ) by means of the relative form of purchasing power parity theory

We furthermore model the export and import of commodities simply as follows:

According to module 9 and the assumptions just made, we have for $c_{1}^{*}=E x / K=C_{1}^{*} / K$ and $c_{2} / \eta=I m / K=C_{2} /(\eta K)$ the expressions:

$$
\begin{aligned}
c_{1}^{*} & =\left(1-\gamma_{c}^{*}(\eta)\right)\left(1-s_{c}^{*}\right)\left(\rho^{*}-t_{c}^{*}\right)\left(l / l^{*}\right) / \eta, \\
c_{2} / \eta & =\left(1-\gamma_{c}(\eta)\right)\left(1-s_{c}\right)\left(\rho-t_{c}\right) .
\end{aligned}
$$

These show that imports as well as exports (the first in terms of the domestic commodity and the second in terms of the foreign good) are both a linear function of the real exchange rate if, for the functions that determine the division of consumption between domestic and foreign goods in both countries, it is furthermore assumed that:

$$
\begin{aligned}
& \gamma_{c}(\eta)=\gamma_{c}+\gamma\left(\eta_{o}-\eta\right), \quad \gamma>0, \\
& \gamma_{c}^{*}(\eta)=\gamma_{c}^{*}-\gamma^{*}\left(\eta_{o}-\eta\right), \quad \gamma^{*}>0,
\end{aligned}
$$

are linear as well, in keeping with our stated desire to express the model in as linear a form as possible. ${ }^{13}$

To simplify even further our treatment of the trade account we assume that:

$$
\eta_{o}=\frac{l_{o}\left(1-\gamma_{c}^{*}\right)\left(1-s_{c}^{*}\right)\left(\rho_{o}^{*}-t_{c}^{*}\right)}{l_{o}^{*}\left(1-\gamma_{c}\right)\left(1-s_{c}\right)\left(\rho_{o}-t_{c}\right)}
$$

This particular choice for $\eta_{o}$ guarantees (as we shall see below) that the steady value of $\eta$ will be $\eta_{o}$ and that the trade account (per unit of capital) $n x=N X / K=(E x-I m) / K=$ $c_{1}^{*}-c_{2} / \eta$ will be balanced in the steady state. ${ }^{14}$

\footnotetext{
${ }^{13}$ Subsequent developments of the model to allow for non-linear adjustments to disequilibrium far off steady state would need to introduce, say, $\tanh$ functions in order to guarantee $\gamma_{c}(\eta), \gamma_{c}^{*}(\eta)$ remain between 0 and 1 at large values of $\left|\eta_{0}-\eta\right|$.

${ }^{14} \mathrm{~A}$ special case that is often employed in the literature on overshooting exchange rates is recovered by making the following sequence of additional assumptions:

- $\beta_{e}=\infty, \beta=\infty$ : so that $\left(1-\tau_{c}\right) r=\left(1-\tau_{c}^{*}\right) r_{o}^{*}+\epsilon$ : Uncovered interest parity (UIP), based on perfect capital mobility, is assumed to hold.
} 
The model can now be rewritten (after some algebraic manipulation) as a nonlinear autonomous dynamic system in the ten state variables $\omega=w / p, l=L / K, p, \pi, \omega^{*}=w^{*} / p^{*}$, $l^{*}=L^{*} / K^{*}, p^{*}, \pi^{*}, e$ and $\epsilon$ :

The domestic economy:

$$
\begin{aligned}
\widehat{\omega} & =\kappa\left[\left(1-\kappa_{p}\right) \beta_{w} X^{w}+\left(\kappa_{w}-1\right) \beta_{p} X^{p}\right], \\
\widehat{l} & =-i(\rho+\pi-r), \\
\widehat{p} & =\kappa\left[\beta_{p} X^{p}+\kappa_{p} \beta_{w} X^{w}\right]+\pi, \\
\dot{\pi} & =\beta_{\pi}\left[\alpha_{\pi}(\hat{p}-\pi)+\left(1-\alpha_{\pi}\right)(-\pi)\right] .
\end{aligned}
$$

Financial and trade links between the two economies:

$$
\begin{aligned}
\hat{e} & =\beta_{e}\left(\beta\left(r^{*}+\epsilon-r\right)-n x(\cdot)\right), \quad \eta=\left(\frac{e p^{*}}{p}\right)^{-1}, \\
\dot{\epsilon} & =\beta_{\epsilon}\left[\alpha_{\epsilon}(\hat{e}-\epsilon)+\left(1-\alpha_{\epsilon}\right)(-\epsilon)\right] .
\end{aligned}
$$

The foreign economy:

$$
\begin{aligned}
\widehat{\omega}^{*} & =\kappa^{*}\left[\left(1-\kappa_{p}^{*}\right) \beta_{w}^{*} X^{w *}+\left(\kappa_{w}^{*}-1\right) \beta_{p}^{*} X^{p *}\right], \\
\widehat{l}^{*} & =-i^{*}\left(\rho^{*}+\pi^{*}-r^{*}\right) \\
\widehat{p}^{*} & =\kappa^{*}\left[\beta_{p}^{*} X^{p *}+\kappa_{p}^{*} \beta_{w}^{*} X^{w *}\right]+\pi^{*} \\
\dot{\pi}^{*} & =\beta_{\pi}^{*}\left[\alpha_{\pi}^{*}\left(\hat{p}^{*}-\pi^{*}\right)+\left(1-\alpha_{\pi}^{*}\right)\left(-\pi^{*}\right)\right] .
\end{aligned}
$$

The following algebraic combinations of the state variables occur on the right-hand sides of this dynamic system:

$$
\begin{aligned}
\rho & =y-\delta-\omega l^{d}=\rho(\omega), y=Y / K, l^{d}=L^{d} / K=y / x=\text { const. } \\
X^{w} & =l^{d} / l-\bar{V}=y /(x l)-\bar{V}, l=L / K, \\
X^{p} & =-Y^{e x s} / K=c_{1}+c_{1}^{*}+i(\cdot)+n+\delta+g-y \\
& =\omega l^{d}+\left(1-s_{c}\right)\left(\rho-t_{c}\right)+i(\cdot)+n+\delta+g+n x(\cdot)-y, \\
i(\cdot) & =i(\rho-r+\pi), \quad r=r_{o}+\left(h_{1} y-m\right) / h_{2}=r(m), \\
c_{1} & =C_{1} / K=\omega l^{d}+\gamma_{c}(\eta)\left(1-s_{c}\right)\left(\rho-t_{c}\right), \\
c_{1}^{*} & =C_{1}^{*} / K=\left(l / l^{*}\right)\left(1-\gamma_{c}^{*}(\eta)\right)\left(1-s_{c}^{*}\right)\left(\rho^{*}-t_{c}^{*}\right) / \eta, \\
n x(\cdot) & =\left(1-\gamma_{c}^{*}(\eta)\right)\left(1-s_{c}^{*}\right)\left(\rho^{*}-t_{c}^{*}\right)\left(l / l^{*}\right) / \eta-\left(1-\gamma_{c}(\eta)\right)\left(1-s_{c}\right)\left(\rho-t_{c}\right), \\
\hat{p}-\pi & =\kappa\left[\beta_{p} X^{p}+\kappa_{p} \beta_{w} X^{w}\right], \quad \hat{p}^{*}-\pi^{*}=\kappa^{*}\left[\beta_{p}^{*} X^{p *}+\kappa_{p}^{*} \beta_{w}^{*} X^{w *}\right]
\end{aligned}
$$

and similarly for the other country. ${ }^{15}$ Note that we always have $n x_{\eta}<0$ due to our assumptions on consumption behavior, i.e., there is no need here for the consideration of

- $\beta_{\epsilon}=\infty, \alpha_{\epsilon}=1:$ so that $\epsilon=\hat{e}:$ Myopic perfect foresight (MPF) with respect to the exchange rate is assumed to hold.

These assumptions are generally assumed in the literature on the Dornbusch model of overshooting exchange rates. Furthermore, the case $\alpha_{\epsilon}=0$ in which $\dot{\epsilon}=\beta_{\epsilon}\left(\hat{e}_{o}-\epsilon\right)$, can be considered as a variant of Dornbusch's original choice of a regressive expectations mechanism: $\epsilon=\beta_{\epsilon}\left(\ln \left(e_{o} / e\right)\right)$, that by differentiation implies the rule $\dot{\epsilon}=\beta_{\epsilon}\left(\hat{e}_{o}-\hat{e}\right)$.

${ }^{15}$ Where in particular:

$$
c_{2}^{*}=C_{2}^{*} / K^{*}=\omega^{*} l^{d *}+\gamma_{c}^{*}(\eta)\left(1-s_{c}^{*}\right)\left(\rho^{*}-t_{c}^{*}\right), \quad c_{2}=C_{2} / K^{*}=\left(l^{*} / l\right)\left(1-\gamma_{c}(\eta)\right)\left(1-s_{c}\right)\left(\rho-t_{c}\right) \eta .
$$




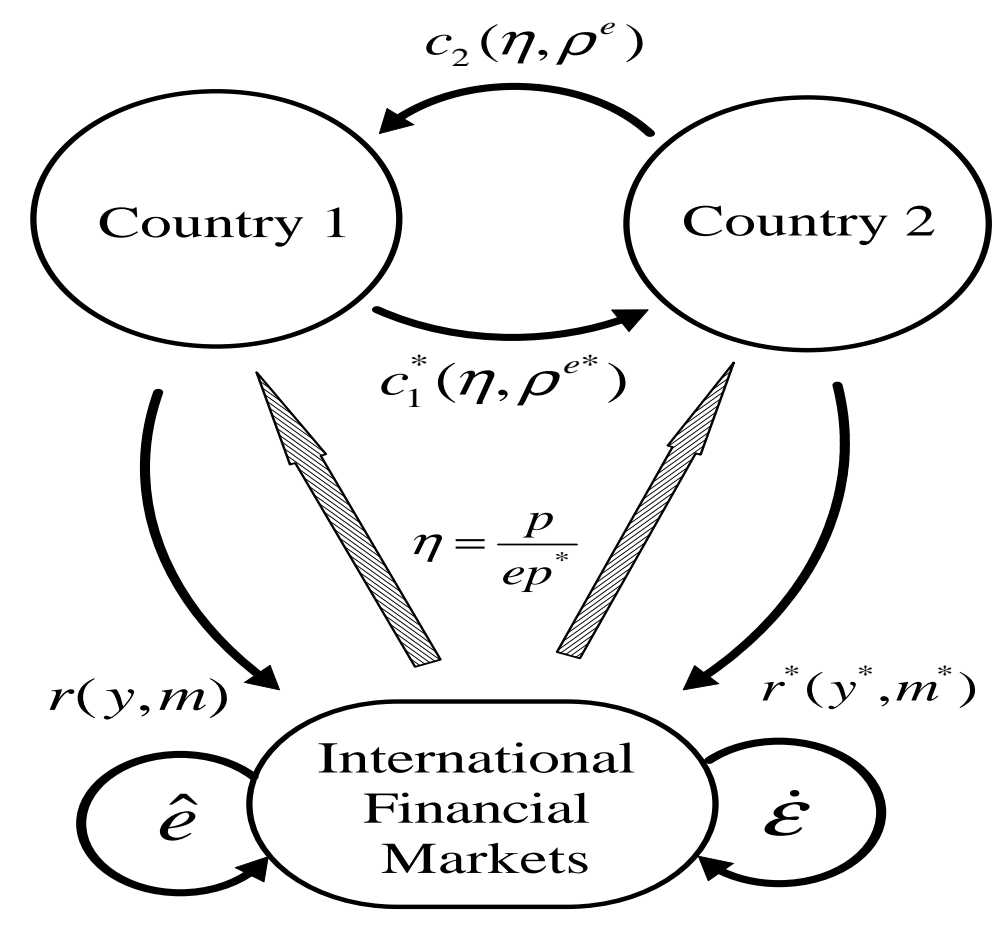

Figure 1: The two country KWG framework

so-called Marshall-Lerner conditions to ensure a normal reaction of net exports with respect to exchange rate changes.

Finally we give a brief graphical summary of the two-country interaction by way of the essential links for trade in commodities and in financial assets. Figure 1 shows the consumption demands for foreign goods, the way the financial markets determine the real exchange rate via the Dornbusch exchange rate dynamics and finally the repercussions back from commodity markets to the financial markets via the interest rates implied by the transactions in the two economies.

Output and real balances per unit of capital determine the domestic as well as the foreign interest rate by way of Keynesian liquidity preference theory. These in turn - together with expected currency depreciation or appreciation and the currency demand originating in the trade account - determine the actual rate of currency depreciation or appreciation (and on this basis also the expected change). Given price levels in the two countries imply a certain real exchange rate whose rate of change is given by inflation at home and abroad and the just determined actual exchange rate dynamics. Inflation at home and abroad are simultaneously determined by demand and cost pressures in the markets for goods and give rise to an international transmission of inflation. Of course we have wage dynamics in addition and also investment and growth, leading overall to a dynamic structure where two Keynes-effects, two Mundell-effects, and two Rose effects interact with

The steady state values of the domestic and the foreign economy depend on the above choice of the steady state real exchange rate. Also here the domestic and the foreign rate of profit must be equal. 
the Dornbusch exchange rate dynamics on the foreign exchange market. The overall effect of this interaction is to create a fairly complex situation of two business cycle mechanisms that interact via trade and via the international financial market.

We show in the next section that the feedback structure in the foreign exchange market is such that a tendency towards cumulative instability is established. This instability may be overcome by the interaction with the real sectors of the two economies.

\subsection{The steady state and its local stability}

In this sub-section we characterize the steady state of the two-country dynamics (53) (62) and its local stability properties. For the details of proofs of the stability results we refer the reader to Asada et al. (2003) (ch.10). ${ }^{16}$

Let us first consider the uniquely determined interior steady state solution of the 10D dynamics $(53)-(62)$ of the preceding section. We disregard the economically meaningless boundary solutions $\omega, l, m=0$, etc. - caused by the growth rate formulation of their laws of motion. In any event these never appear as attractors in the numerical investigations to be performed later. Furthermore, the local dynamics will all be constrained to a neighborhood of the unique interior steady state or point of rest of the simplified dynamics (53) - (62) fulfilling $\omega_{0}, l_{0}, m_{0} \neq 0$. This steady-state is given by: ${ }^{17}$

$$
\begin{aligned}
l_{0} & =l^{d} / \bar{V}=y /(x \bar{V}), \\
m_{0} & =h_{1} y, \quad \pi_{0}=\mu-n, \\
\rho_{0} & =t_{c}+\frac{n+g-t_{c}}{s_{c}}, \quad r_{o}=\rho_{o}+\pi_{o}, \\
\omega_{0} & =\left(y-\delta-\rho_{0}\right) / l^{d},
\end{aligned}
$$

for the domestic economy with corresponding expressions for $\omega^{*}, l^{*}, m^{*}, \pi^{*}, r^{*}, \rho^{*}$ in the foreign economy, and

$$
\begin{aligned}
\eta_{o} & =\frac{l_{o}\left(1-\gamma_{c}^{*}\right)\left(1-s_{c}^{*}\right)\left(\rho_{o}^{*}-t_{c}^{*}\right)}{l^{*}\left(1-\gamma_{c}\right)\left(1-s_{c}\right)\left(\rho_{o}-t_{c}\right)}, \\
\epsilon_{o} & =\mu-n-\left(\mu^{*}-n\right)=\mu-\mu^{*}=\hat{e}_{o} .
\end{aligned}
$$

We assume that the parameters of the model are chosen such that the steady state values for $\omega, l, m, \rho, r, \eta$ (and the corresponding foreign economy quantities) are all positive. Note also that $\pi_{0}=\mu_{0}-n$ should be large enough such that $r_{0}>0$.

The following two theorems tell us how the local stability / instability conflict between the four basic feedback channels manifests itself through the relative speeds of adjustment of

\footnotetext{
${ }^{16}$ The stability analysis of such a high order dynamical system is possible because of the simplifying assumptions made in section 3.1

${ }^{17}$ Note again that $y, l^{d}$ are given magnitudes in the KWG dynamics being employed here.
} 
the various dynamic adjustment processes involved in these channels. The proofs of the theorems are provided in Asada et al. (2003).

\section{Theorem 1}

Assume that the parameters $\beta_{\epsilon}, \beta_{e}, \beta, \beta_{\pi}, \beta_{\pi}^{*}, \beta_{p}, \beta_{p}^{*}$ are all chosen sufficiently small. Then:

1. The determinant of the Jacobian at the steady state of the considered 10D dynamics is always positive.

2. The considered 10D dynamics exhibit ten eigenvalues with negative real parts, i.e., their interior steady state solution is locally asymptotically stable in the considered situation.

\section{Theorem 2}

From the locally asymptotically stable situation of theorem 1, the steady state must lose its local stability by way of Hopf-bifurcations ${ }^{18}$ if one of the parameters $\beta_{\pi}$ (carrying the destabilizing Mundell effect), $\beta_{\epsilon}$ (carrying the destabilizing Dornbusch effect) or $\beta_{p}$ (carrying the destabilizing Rose effect) is made sufficiently large. The latter however holds only in the case where the real wage effect in investment demand dominates the real wage effect in consumption demand.

Thus fast adjustments of expectations and fast adjustments of prices (in the case of a negative dependence of aggregate demand on the real wage level) will lead to loss of local stability, which is always accompanied by business cycle fluctuations (possibly persistent ones) if a supercritical Hopf-bifurcation occurs, which the simulations below indicate is usually the case. But generally these fluctuations will be explosive as long as only intrinsic nonlinearities are present. To obtain bounded dynamics in such situations it is necessary to introduce additional extrinsic nonlinearities, such as asymmetries in the money wage Phillips curve. Numerical simulations can then be used to gain insights into the global dynamics, and these indicate that stable limit cycle situations or persistent cycles can frequently be generated.

\section{Numerical Investigation of The Model}

As discussed in the previous section the important destabilizing mechanisms are the Mundell effect, the Dornbusch effect and the Rose effect which are carried by the parameters $\beta_{\pi}, \beta_{\epsilon}$ and $\beta_{p}$, characterizing the adjustment of inflation and exchange rate expectations and prices, respectively (see modules 7 and 8 in section 2.1). These effect are most easily seen by considering the variation in the maximum real part of the eigenvalues of the Jacobian matrix of the 10D system (53)-(62) as a function of these parameters, which are displayed in figure 2. There we see that the cross over from local stability to instability

\footnotetext{
${ }^{18} \mathrm{~A}$ Hopf-bifurcation occurs in a continuous time dynamical system if, as a result of a smooth change of a parameter, the change from local stability to local instability is accompanied by the birth of a limit cycle around the steady state. We refer the reader to Guckenheimer and Holmes (1983) for technical details and for some economic interpretation to Kind (1999).
} 


\begin{tabular}{|c|c|c|c|c|c|c|}
\hline \multicolumn{7}{|c|}{ Real-Sector } \\
\hline$\mu=0.05$ & $s_{c}=0.8$ & $t_{n}=0.35$ & $g=0.35$ & $n=0.05$ & $\delta=0.1$ & $m_{\text {shock }}=1.1$ \\
\hline$\mu^{*}=0.05$ & $s_{c}^{*}=0.8$ & $t_{n}^{*}=0.35$ & $g^{*}=0.35$ & $n^{*}=0.05$ & $\delta^{*}=0.1$ & $m_{\text {shock }}^{*}=1.0$ \\
\hline$y_{p}=1$ & $x_{p}=2$ & $i=0.5$ & $\bar{V}=0.8$ & $h_{1}=0.1$ & $h_{2}=0.2$ & \\
\hline$y_{p}^{*}=1$ & $x_{p}^{*}=2$ & $i^{*}=0.5$ & $\bar{V}^{*}=0.8$ & $h_{1}^{*}=0.1$ & $h_{2}^{*}=0.2$ & \\
\hline \multicolumn{7}{|c|}{ "Wage-Price Dynamics } \\
\hline$\beta_{w}=1$ & $\beta_{p}=1$ & $\beta_{\pi}=0.5$ & $\kappa_{w}=0.5$ & $\kappa_{p}=0.5$ & $\alpha_{\pi}=0.5$ & \\
\hline$\beta_{w}^{*}=2$ & $\beta_{p}^{*}=1$ & $\beta_{\pi}^{*}=0.5$ & $\kappa_{w}^{*}=0.5$ & $\kappa_{p}^{*}=0.5$ & $\alpha_{\pi}^{*}=0.5$ & \\
\hline \multicolumn{7}{|c|}{ Exchange Rate Dynamics } \\
\hline$\beta_{e}=1$ & $\beta=2.0$ & $\beta_{\epsilon}=1$ & $\alpha_{\epsilon}=0.1$ & & & \\
\hline \multicolumn{7}{|c|}{ Trade Sector } \\
\hline$\gamma=0.99$ & $\gamma_{c}=0.5$ & & & & & \\
\hline$\gamma^{*}=0.99$ & $\gamma_{c}^{*}=0.5$ & & & & & \\
\hline
\end{tabular}

Table 2: The Standard Parameter Set

(indicated by the maximum real part of the eigenvalues becoming positive) occurs at quite moderate values and certainly in ranges of empirical estimates of these parameters.

The standard parameter set, around which we base our simulations, is displayed in Table 2 . The values have been chosen using various rationales. The parameters for the real sector are based on plausible values for these quantities for real economies. It is more difficult to find plausible values for the speed of adjustment parameter (the various $\beta$ coefficients) for the wage-price dynamics and exchange rate dynamics. The values we have chosen for the real sector are broadly consistent with the range suggested by the empirical studies of Flaschel and Krolzig (2003) and Flaschel, Gong and Semmler (2001). The value for the $\beta$ coefficient in the exchange rate dynamics are more "guesstimates" based on the expectation that magnitudes of speed of adjustment would be in the same ball park as the wage-price dynamics but larger because the foreign exchange market adjusts very rapidly, as it incorporates almost immediately changes in expectations and interest rates.

Figure 2 illustrates the content of theorem 2 in a particular situation. Taking the standard parameter set in table 2 the maximum real part of the eigenvalues of the Jacobian is plotted as a function of $\beta_{p}$ (carrying the Rose effect), $\beta_{\pi}$ (carrying the Mundell effect) and $\beta_{\epsilon}$ (carrying the Dornbusch effect). In each case as the parameter increases from zero, local stability changes to local instability. It is interesting to note that in the cases of $\beta_{p}$ and $\beta_{\pi}$, local stability is recovered at higher values. This does not contradict theorem 2 which simply asserts what happens as the $\beta$ 's increase by sufficiently small amounts around the point where local stability is lost.

Of particular interest are the global dynamics once the economy enters the locally unstable region. Many simulations (not reported here) indicate that generally the intrinsic nonlinearities of the model are not sufficient to bound the dynamics in such situations. It is necessary to introduce at least one extrinsic non-linearity. In the following we will make 

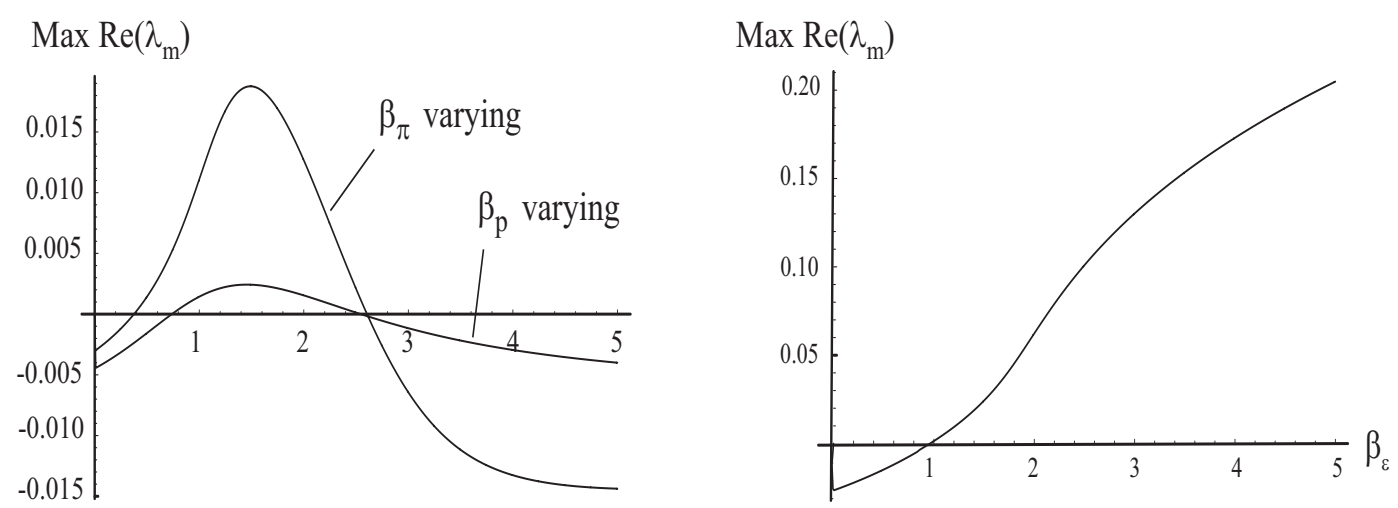

Figure 2: The Maximum Real Part of the Eigenvalues: Illustrating the Rose, Dornbusch and Mundell Effects via the loss of local stability. Note that the Rose and Mundell Effects are reversed at higher values of $\beta_{p}$ and $\beta_{\pi}$ respectively

use of one prominent behavioral nonlinearity, already discussed in Keynes (1936), namely a kinked money wage Phillips curve, expressing in stylized form the fact that wages are much more flexible upwards than downwards.

To model the wage dynamics in this situation, i.e. to introduce downward wage rigidity, we need to modify (33) to

$$
\hat{w}=\min \left\{\beta_{w}(V-\bar{V})+\kappa_{w} \hat{p}_{w}+\left(1-\kappa_{w}\right) \pi_{w}, 0\right\},
$$

where here we are assuming a wage floor of 0 . There will be an analogous equation for the foreign sector.

In closed economy models this nonlinearity has been shown to be sufficient to limit the dynamics to economically viable domains, see for example Chiarella and Flaschel (1996b) for more details on the wage kink. The downward nominal wage rigidity is often sufficient to overcome the destabilizing feedback channels of Mundell-type or Rose-type and thus succeeds in bounding the economic fluctuations in a certain area outside the steady state. This holds if wages are assumed to be completely inflexible in the downward direction and if there is zero steady state inflation (where they can even stabilize an economy towards damped oscillations that would otherwise - without this inflexibility - break down immediately).

In figures 3 to 7 we demonstrate the effects of various parameter configurations on the international business cycle given by the model and the existence of parameter constellations for which persistent synchronization of international business cycles and high variability in the term of trade are observed. In each simulation ${ }^{19}$ the models are started at the steady state and solved with weekly time increments, though the units on the horizontal axes are years. At $t=1$ a monetary shock occurs either in the domestic economy, the foreign economy or both. The differences between the parameters $m_{\text {shock }}$ and $m_{\text {shock }}^{*}$ and unity indicate the percentage changes in the respective monetary growth rates.

\footnotetext{
${ }^{19}$ The simulations that follow were performed using the SND software package described in Chiarella, Flaschel, Khomin and Zhu (2002), which can be downloaded together with the project files for the simulations of this paper from http//:www.business.uts.edu.au/finance/staff/carl.html.
} 

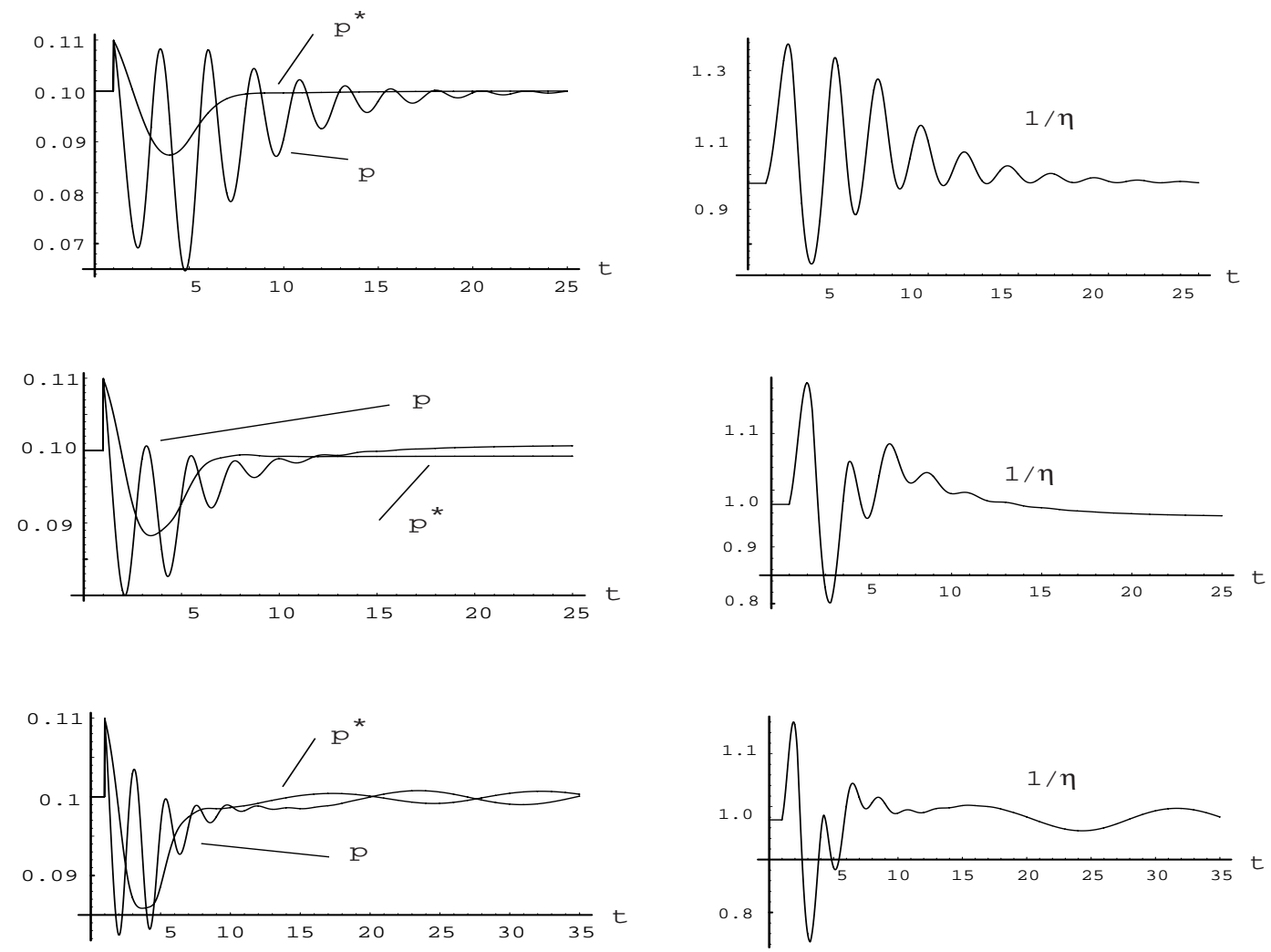

Figure 3: Two country cycles: Time series for $p, p^{*}$ and terms of trade $1 / \eta$. Isolated economies (top); with trade interactions (middle)-note the increased stability; and finally with exchange rate dynamics added (bottom)-note the adverse phase synchronization. 

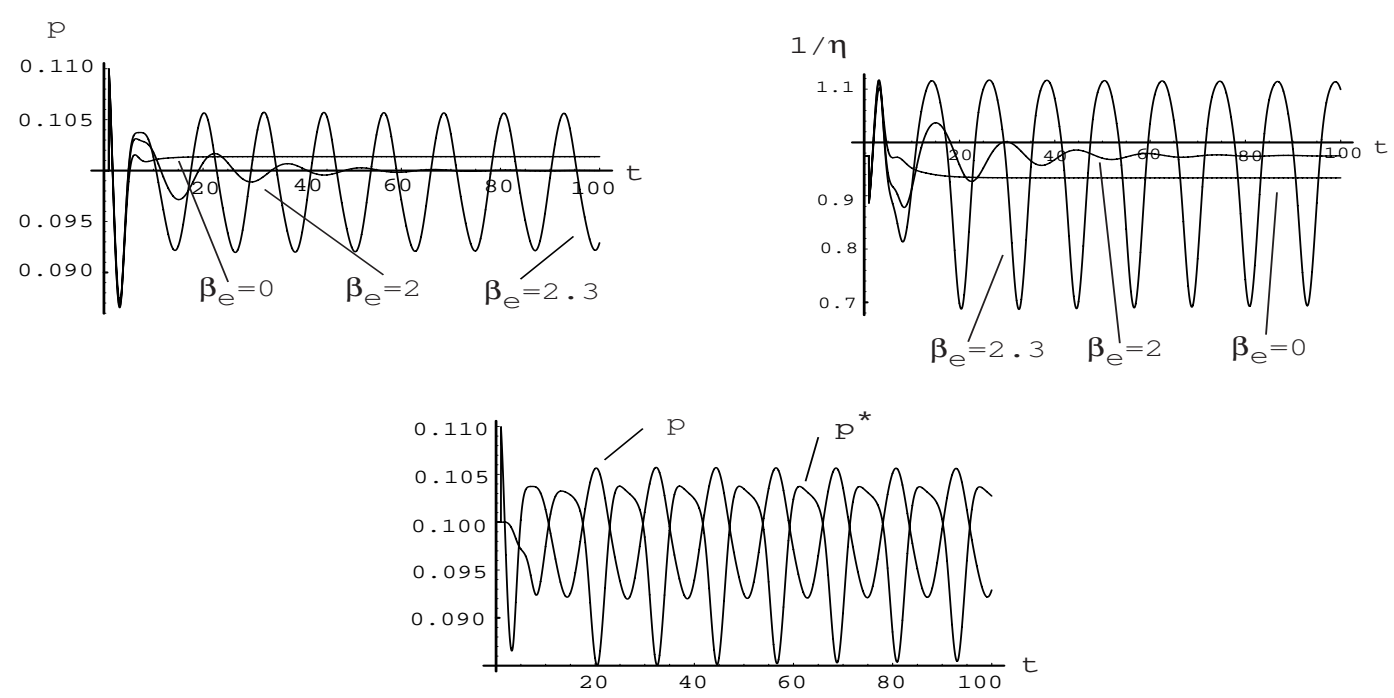

Figure 4: The occurrence of limit cycles in domestic price and terms of trade as $\beta_{e}$, the speed of exchange rate adjustment, increases (top panels) and of the negative transmission of price fluctuations between the two countries (bottom panel).

We show in Figure $3^{20}$ (top) the time series for the prices $p$ and $p^{*}$, when both countries are still completely decoupled from each other with country 1 exhibiting the larger fluctuations (and shorter phase length) in this state variable. We also display the terms of trade $1 / \eta$, which display high variability before settling down. Due to the strict kink in the money wage Phillips curve we have a marked convergence to the steady state in both countries. Allowing next for trade in goods between the two countries (but not yet for financial links) dampens the cycle in country 1 considerably and makes the one in country two slightly more pronounced, as shown in Figure 3 (middle). The terms of trade also settle down more quickly. These effects remain true if financial links are added (Figure 3 bottom). Now, however, the prices and terms of trade converge to a limit cycle, but of very small amplitude. This limit cycle exhibits nearly completely adverse phase synchronization in prices, since the exchange rate dynamics now dominate the outcome and produce the negative correlation in price dynamics. There is, thus, no positive international transmission of price movements, contrary to what is generally expected, if trade is dominated by exchange rate movements and their (always adverse) effect on one of the two countries.

In Figure $4^{21}$ we show, with the time series in the top graph, that increasing speed of exchange rate adjustment produces increasing volatility, here shown for the domestic country price $p$ and for the terms of trade $1 / \eta$. The final outcome (at $\beta_{e}=2.3$ ) is convergence to a persistent business cycle (stable limit cycle) in both countries, yet - as the lower time series (with $\beta_{e}=2.3$ ) show - with nearly perfect negative correlation. This figure again demon-

\footnotetext{
${ }^{20}$ The changes to the parameter set in Table 2 for this simulation run are as follows [the modifications (1) in trade $\left(\gamma_{c}, \gamma\right)$ and (2) in financial links $\left(\beta, \beta_{e}, \beta_{\epsilon}\right)$ are shown in brackets]: $\beta_{w}=2, \beta_{p}=5, \beta_{e}=$ $0\left(\beta_{e}=1\right), \quad \beta=0(\beta=2.3), \quad \beta_{\epsilon}=0\left(\beta_{\epsilon}=1\right), \quad \beta_{\pi}=3, \quad \beta_{\pi}^{*}=3, \quad \gamma=0(\gamma=1), \quad \gamma^{*}=0\left(\gamma^{*}=1\right), \quad \gamma_{c}=$ $1\left(\gamma_{c}=0.5\right), \quad \gamma_{c}^{*}=1\left(\gamma_{c}^{*}=0.5\right)$.

${ }^{21}$ The changes to the parameter set in Table 2 for this simulation run are as follows: $\beta_{w}=2, \quad \beta_{w}^{*}=$ $1, \beta_{p}^{*}=1, \beta_{e}=2.3, \quad \beta_{\pi}=3, \beta_{\pi}^{*}=2, i=0.7, \quad i^{*}=0.7$.
} 

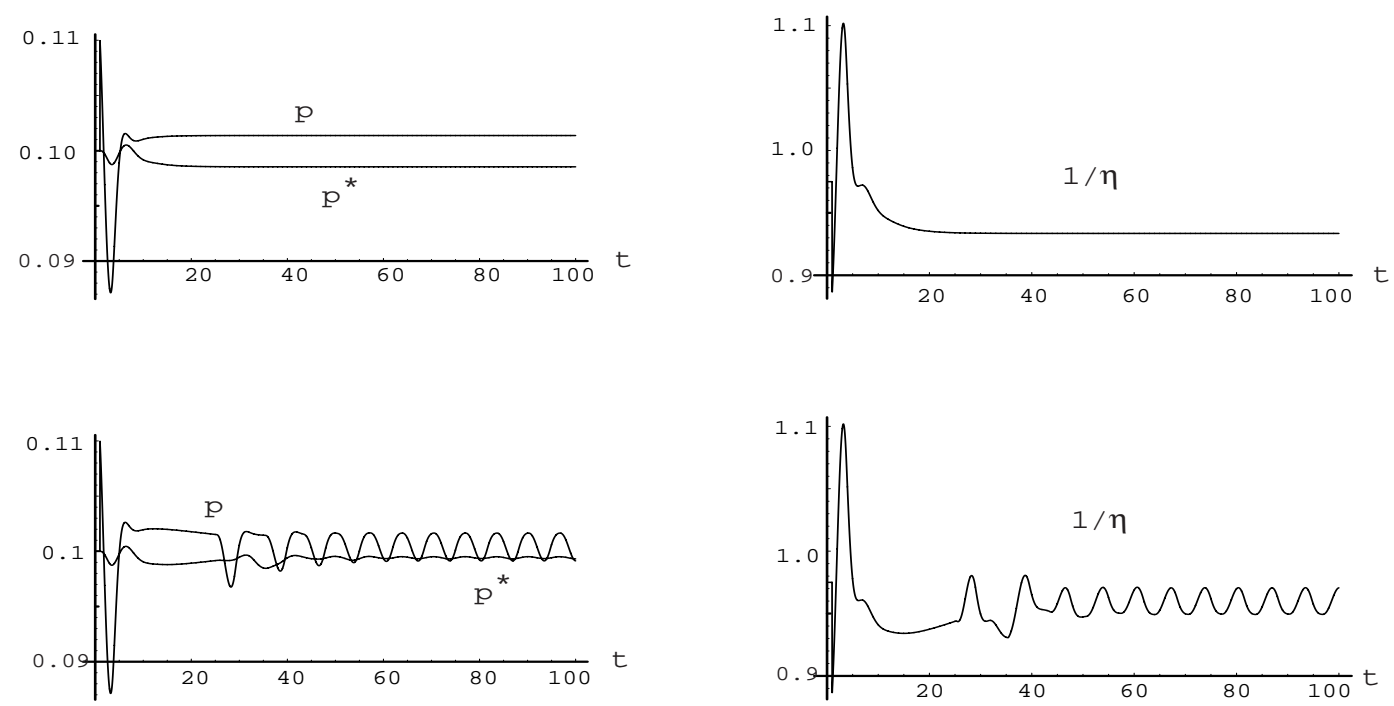

Figure 5: The international transmission of persistent economic fluctuations due to positive steady state inflation in the domestic country. In the top panels there is a $0 \%$ steady state inflation policy in both countries. The bottom panels allow for $0.7 \%$ steady state inflation in the domestic country.

strates that business fluctuations need not at all be synchronized with respect to upswings and downswings, though they are clearly synchronized here with respect to phase length. Note that setting $\beta_{e}=0$ (no exchange rate dynamics) is already sufficient to decouple the real dynamics from what is occurring in the foreign exchange market.

Figure $5^{22}$ shows in its upper part that radically damped price oscillations may only occur in the case where both countries pursue a policy of zero steady state inflation (by setting $\mu=n$ and $\mu^{*}=n^{*}$ ). In the lower part however we show what happens if country one allows for 0.7 percent inflation in the steady state by increasing its money supply growth rate accordingly. There are now persistent price fluctuations not only occurring in the country that allows for such monetary policy, but also induced (although smaller) persistent fluctuations in the other country, here with a certain degree of phase synchronization, since the Dornbusch dynamics are again absent from this situation $\left(\beta_{e}=\beta_{\epsilon}=0\right)$. The price fluctuations are of course reflected in the terms of trade.

In Figure $6^{23}$ (top left) we show how cycles for countries that are interacting with respect to trade (in a fixed exchange rate system) are to some extent synchronized (with respect to peaks and troughs in price movements). This synchronization is almost completely reversed (bottom left) in the case of a flexible exchange rate system $\left(\beta_{e}=\beta=\beta_{\epsilon}=0.5\right)$. The figures on the right show that the terms of trade become somewhat more variable under flexible

\footnotetext{
${ }^{22}$ The changes to the parameter set in Table 2 for this simulation run are as follows: $\beta_{w}=2, \quad \beta_{w}^{*}=$ $1, \beta_{e}=0, \beta=0, \beta_{\varepsilon}=0, \beta_{\pi}=3, \quad \beta_{\pi}^{*}=2, \quad \mu=0.06, \quad i=0.7, \quad i^{*}=0.7$.

${ }^{23}$ The changes to the parameter set in Table 2 for this simulation run are as follows: $\beta_{w}=3, \quad \beta_{p}=$ $1.5, \quad \beta_{w}^{*}=0.6, \beta_{p}^{*}=1.5, \quad \beta_{e}=0, \quad \beta=0, \quad \beta_{\varepsilon}=0, \quad \beta_{\pi}=3, \beta_{\pi}^{*}=3, \quad \mu=0.06, \quad i=0.7, i^{*}=0.7, \quad \gamma=$ $1.5, m_{\text {shock }}^{*}=1.1$.
} 

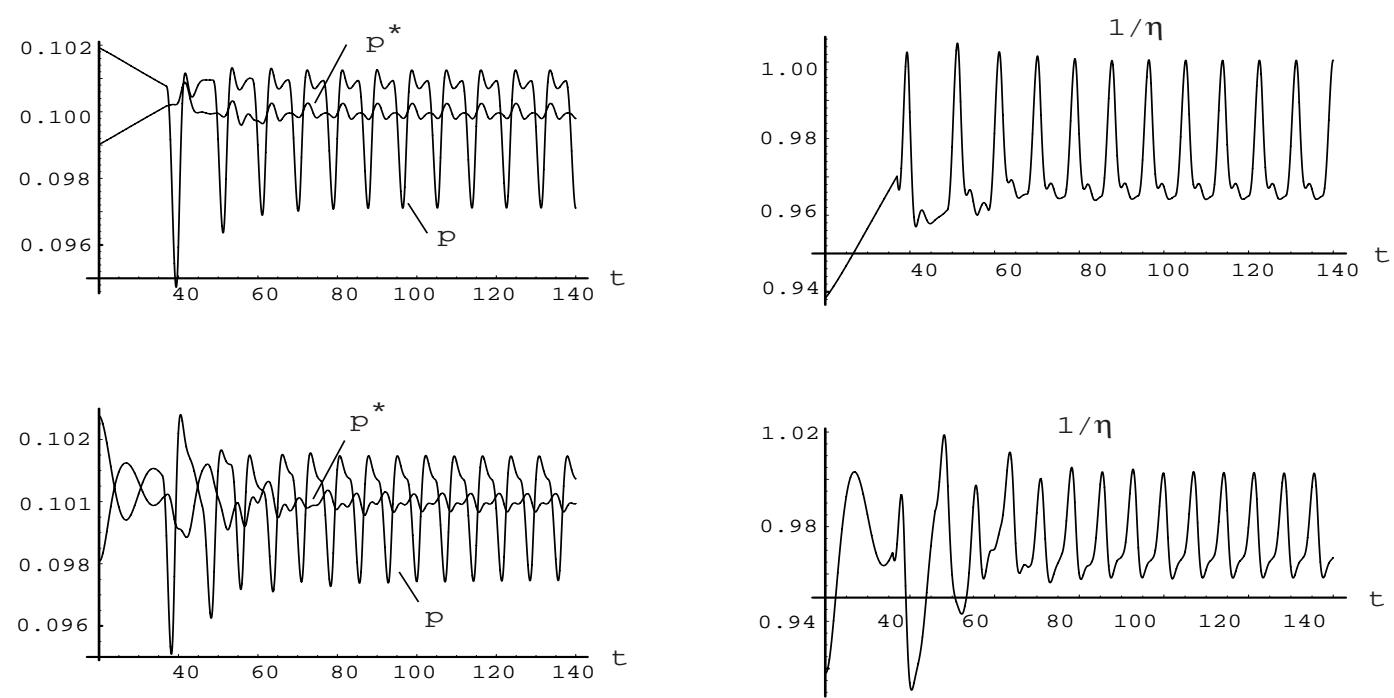

Figure 6: Phase synchronization in a fixed exchange rate system (top panels) and its loss under flexible exchange rates bottom panels.

exchange rates. The volatility exhibited here suggests that cycle interaction in the real and the financial sector thus may make such interacting economies fairly volatile. ${ }^{24}$

Figure $7^{25}$ shows in striking fashion how very small variations in the growth rate of the money supply at home or abroad can have dramatic consequences on the dynamic outcomes of the model. Top left shows a limit cycle outcome for inflation that occurs when both economies set the money supply growth rate so as to have zero steady state inflation. In the place of the limit cycle we see recurrent fluctuations (top right) when the growth of the domestic money supply $(\mu)$ is changed from 0.05 to 0.051 , while the dynamics are very close to the steady state in between the irregular fluctuations. Eigenvalue diagrams (similar to Figure 2) indeed confirm a very sensitive behavior of the maximum eigenvalue with respect to the growth rate of the money supply where there is zero steady state inflation.

In the opposite situation where $\mu^{*}$ is changed from 0.05 to 0.051 by contrast we get convergence to the steady state within the first 150 years, but finally economic breakdown (after 700 years) due to a very small positive root of the dynamics. This contrasting effect is a consequence of the nonlinearity of the system and the asymmetry of the domestic country and foreign country adjustment parameters. Other simulations (not reported) indicate that this breakdown can be delayed a bit if the growth rate of domestic money supply is also changed to 0.051 .

Figure 7 finally shows in its bottom panels cases of very minor steady state deflation. When there is steady state deflation in the domestic economy $\left(\mu=0.049, \mu^{*}=0.05\right)$, which is characterized by high speeds of adjustments in the wage price module of the model, we

\footnotetext{
${ }^{24}$ Fixed and flexible exchange rate regimes are compared in Baxter and Stockman (1989), Gerlach (1988) and Greenwood and Williamson (1989). A two-country analysis for a fixed exchange rate regime that is very much in the spirit of the model used here is provided in Asada (2003).

${ }^{25}$ The changes to the parameter set in Table 2 for this simulation run are as follows: $\beta_{w}=3 ; \beta_{p}=3 ; \beta_{\pi}=$ $3 ; \beta_{w}^{*}=1 ; \beta_{\pi}^{*}=3 ; \beta_{e}=2 ; \beta=1.2 ; \beta_{\epsilon}=1 ;$
} 

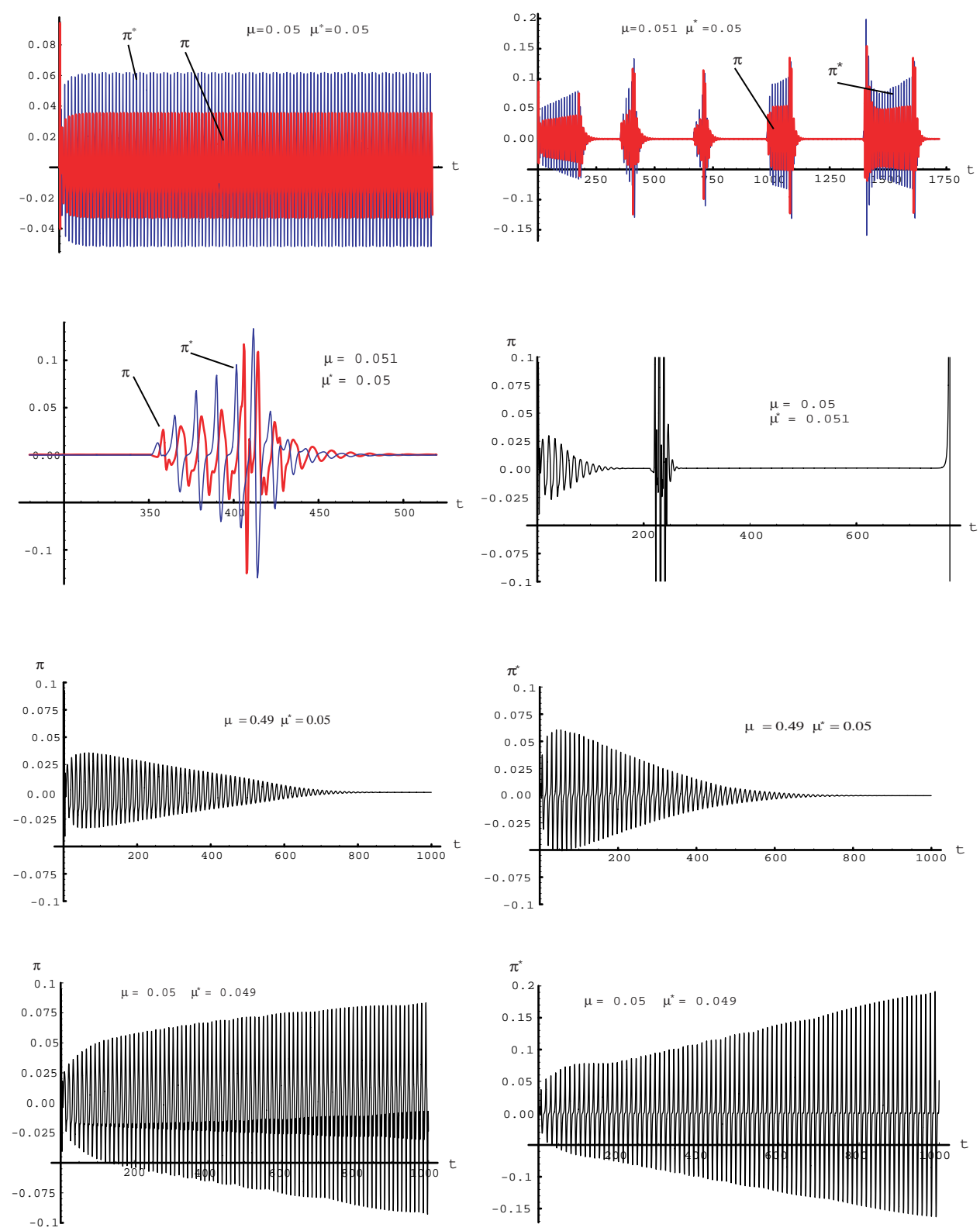

Figure 7: The impact on inflation of differing monetary growth rate policies in the two countries 
now get convergence to the steady state. In the case of deflationary policy in the foreign economy $\left(\mu=0.05, \mu^{*}=0.049\right)$ we however get instability. We stress finally that the cycle length in the time series is approximately ten years and that this phase length tends to become longer the more sluggish wages (and prices) become. The asymmetric behaviour with respect to money supply policy in the two countries is probably due to the asymmetry in the parameter set, in particular we note that $\beta_{p}=3$ whilst $\beta_{p}^{*}=1$.

This concludes the numerical illustrations provided in this section for the case of two coupled KWG economies, where interacting wage-price dynamics have been the main focus of interest (coupled with income-distribution driven accumulation dynamics), but where the quantity dynamics of the KMG modelling framework are still absent in this formulation of full capacity growth.

\section{Conclusions}

In this paper we have developed a model of two country business fluctuations within the non-market clearing or disequilibrium tradition. Within each country the dynamics are driven by three main feedback chains; the Keynes real interest rate effect, the Mundell real rate of interest effect and the Rose real wage effect. The first of these is generally stabilizing, the second generally destabilizing, and the third may be stabilizing or de-stabilizing. In order to simplify the interaction between the various feedback mechanisms and also to reduce the size of the dynamic system to be analyzed we have suppressed the other important feedback chain in models of this type, namely the Metzler inventory effect. The feedback chain linking the two countries is the Dornbusch capital gains accelerator effect, that is generally destabilizing. The dynamics of the two country economic interactions are thus driven by these four feedback chains with conflicting stabilizing and destabilizing tendencies. We identify the key parameters driving these effects as the speeds of adjustment in various sub-markets of the model. For sufficiently low values of all speeds of adjustment the two country economy is stable. However a sufficiently large ceteris-paribus increase in any of the speeds of adjustment determining the destabilizing tendencies will in fact destabilize the economy via a Hopf bifurcation, leading to economic fluctuations in both countries. In order to bound these fluctuations we have introduced one particular non-linearity, namely, a kink in the Philips wage curve reflecting the observed institutional feature that nominal wages are flexible upwards but inflexible downwards.

In order to gain some insights into its global dynamics we have simulated the model. The simulations illustrate the role of the Dornbusch effect in propagating price movements between the two countries and its influence on price volatility. The simulations also show how small differences in monetary policy in the two countries can have quite different effects on the business cycle of each country. In all simulations we have also displayed the terms of trade and seen that these can exhibit the high variability that is one of the stylized facts of the international business cycle. In particular we have seen from Figure 3 that trade and financial linkages can increase stability but that the financial linkages can induce adverse phase synchronization. Figure 4 shows how an increase in the speed of exchange rate adjustments can bring about increased volatility in prices and terms of trade. Again the adverse phase synchronization of prices is evident. Figure 5 demonstrates that with one country (here the domestic economy) moving only slightly from a zero steady 
state inflation policy can bring about fluctuations in prices in both countries and in terms of trade that would otherwise remain at their steady state values. Figure 6 compares fixed and flexible exchange rate systems and demonstrates that positively correlated price fluctuations under a fixed exchange rate regime can become negatively correlated under a flexible regime. At the same time the terms of trade display more variability under the flexible exchange rate regime. Figure 7 demonstrates that small changes in the monetary growth rate targets of both regimes can lead to largely different outcomes for fluctuations in inflationary expectation.

Future work in this area would need to also include the Metzler inventory feedback channel. The resulting dynamic system is of dimension 14 and its highly intertwined feedback mechanisms make it difficult to obtain clear cut analogues of theorems 1 and 2 of this paper. It will be necessary to rely more heavily on eigenvalue diagrams similar to figure 2 and direct simulations of the model to understand its cycle generating tendencies. It would also be of interest to explore other extrinsic non-linearities to bound the potentially explosive dynamics of the model in its regions of local instability. For instance in the foreign trade sector non-linear versions of equations (50) and (51) for the share of domestic goods in the consumption of asset holders. It is also important to empirically estimate models of the type in this paper, which would involve extending to the two country situation the approach of Flaschel, Gong and Semmler (2001).

\section{Notation}

The following list of symbols contains only domestic variables and parameters. Magnitudes referring to the foreign country are defined analogously and are indicated by an asterisk (*), while domestic and foreign commodities are distinguished by the indices 1 and 2 , respectively. Real magnitudes are generally expressed in terms of the domestic good when composite commodities are considered. We use $w$ and $c$ as index to characterize magnitudes that refer to workers and pure asset holders respectively, while indices $p, f$ and $g$ refer to private households, firms and the government. Superscript $d$ characterizes demand expressions, while the corresponding supply expressions do not have any index (in order to save notation).

A. Statically or dynamically endogenous variables:

$\begin{array}{ll}Y & \text { output } \\ Y^{p} & \text { potential output } \\ Y^{d} & \text { aggregate demand } C+I+\delta K+G \\ Y_{c}^{D} & \text { disposable income of asset-holders } \\ L^{d} & \text { employment } \\ L & \text { labor supply } \\ V=L^{d} / L & \text { rate of employment }(\bar{V} \text { the employment-complement } \\ C=C_{w}+C_{c} & \text { of the NAIRU) } \\ C_{1} & \text { private consumption } \\ C_{2} & \text { consumption of the domestic good } \\ S_{p}=S_{w}+S_{c} & \text { consumption of the foreign good }\end{array}$




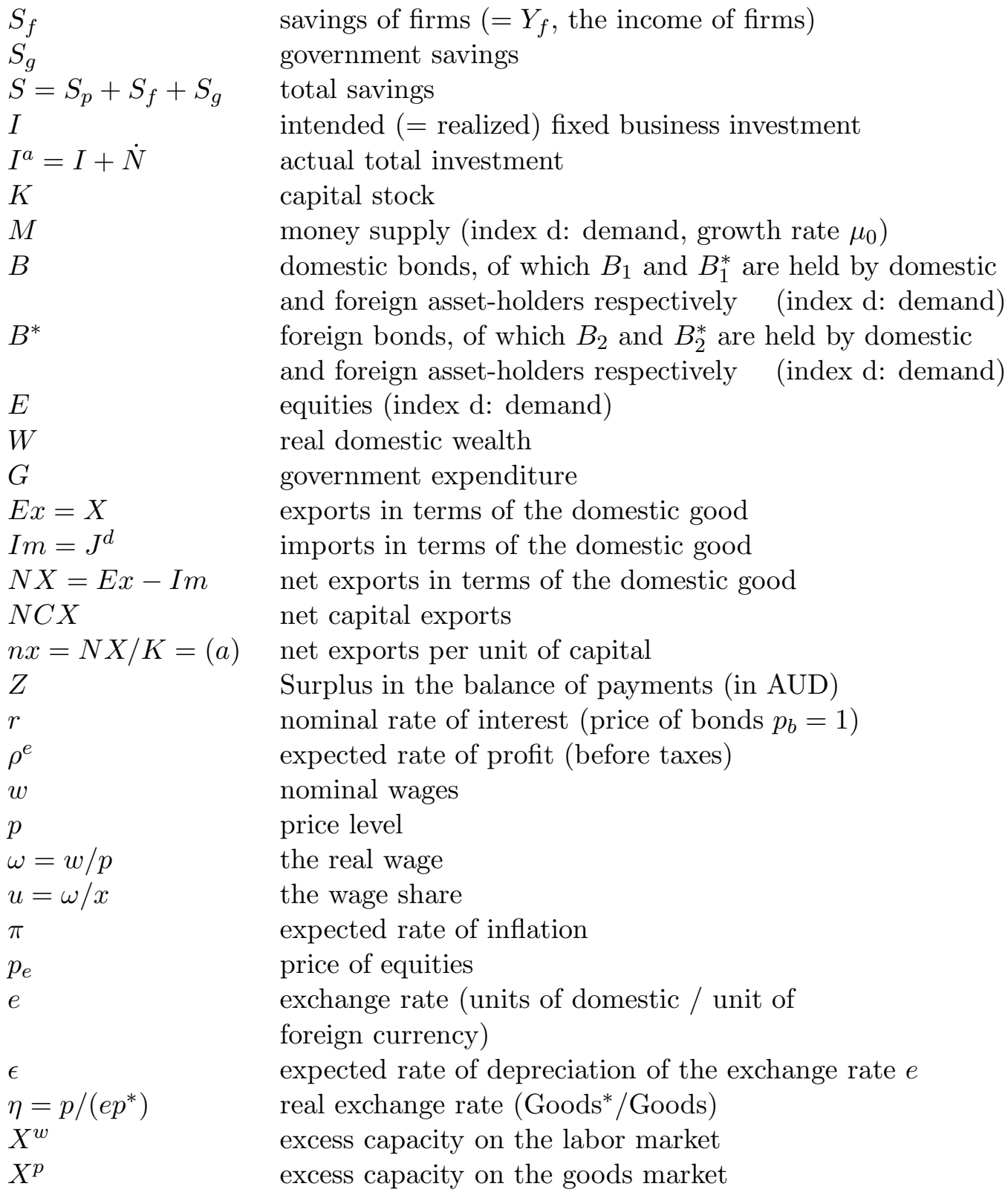

B. Parameters of the model

$\begin{array}{ll}\bar{V} & \text { NAIRU-type normal utilization rate concept (of labor) } \\ \delta & \text { depreciation rate } \\ \bar{\mu}(=\mu) & \text { steady growth rate of the money supply } \\ n & \text { natural growth rate } \\ i & \text { investment parameter } \\ h_{1}, h_{2} & \text { money demand parameters } \\ \beta_{w} & \text { wage adjustment parameter } \\ \beta_{p} & \text { price adjustment parameter } \\ \beta_{\pi} & \text { inflationary expectations adjustment parameter } \\ \beta_{e} & \text { exchange rate adjustment parameter } \\ \beta & \text { disequilibrium measure in international capital flows } \\ \beta_{\epsilon} & \text { adjustment parameter of exchange rate expectations } \\ \alpha & \text { weights for forward and backward looking expectations }\end{array}$




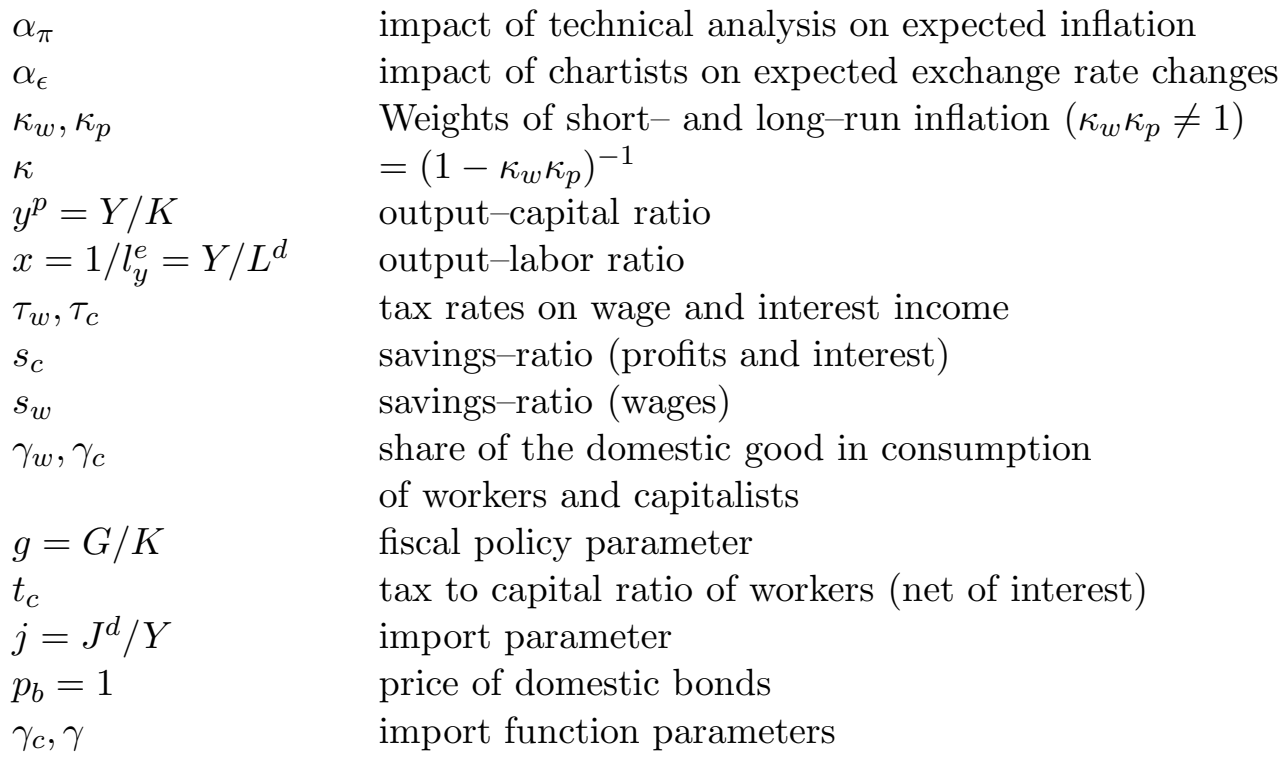

C. Further notation

$\begin{array}{ll}\dot{x} & \text { time derivative of a variable } x \\ \widehat{x} & \text { growth rate of } x \\ l^{\prime}, l_{w} & \text { total and partial derivatives } \\ y_{w}=y^{\prime}(l) l_{w} & \text { composite derivatives } \\ r_{o}, \text { etc. } & \text { steady state values }\left(\bar{r} \text { parameter which may differ from } r_{o}\right) \\ y=Y / K, \text { etc. } & \text { real variables in intensive form } \\ m=M /(p K), \text { etc. } & \text { nominal variables in intensive form }\end{array}$

\section{References}

AsadA, T. (2003): An interregional dynamic model. The case of fixed exchange rates. Studies in Regional Science, forthcoming.

Asada, T., Chiarella, C., Flaschel, P. and R. Franke (2003): Open Economy Macrodynamics. An Integrated Disequilibrium Approach Heidelberg: Springer.

Backus, D. K., Kehoe, P. J. and F.E. Kydland (1995): International Business Cycles: Theory and Evidence, Essay 11 in Cooley (1995).

Baxter, M. and A.C. Stockman (1989): Business cycles and the exchange rate regime: some international evidence. Journal of Monetary Economics, 23, 377 - 400.

Brenner, T., Weidlich, W. and U. WitT (2002): International co-movements of business cycles in a 'phase-locking' model. Metroeconomica, 53, 113 - 138.

CAnova, C. and J. Marrinan (1998): Sources and Propagation of International Output Cycles: Common Shocks or Transmission. Journal of International Economics, 46, 133 - 166.

Chiarella, C. and P. Flaschel (1996a): Real and monetary cycles in models of KeynesWicksell type. Journal of Economic Behaviour and Organization, 30, 327 - 351. 
Chiarella, C. and P. Flaschel (1996b): An integrative approach to prototype 2D-macromodels of growth, price and inventory dynamics. Chaos, Solitons \& Fractals, 7, $2105-$ 2133 .

Chiarella, C. and P. Flaschel (2000): The Dynamics of Keynesian Monetary Growth: Macro Foundations. Cambridge, UK: Cambridge University Press.

Chiarella, C., Flaschel, P., Groh, G. and W. Semmler (2000): Disequilibrium, Growth and Labor Market Dynamics. Macro Perspectives. Berlin: Springer.

Chiarella, C., Flaschel, P., Khomin, A. and P. Zhu (2002): The SND Package: Applications to the Dynamics of Keynesian Monetary Growth. Bern: Peter Lang.

Cooley, T.F. (1995): Frontiers of Business Cycle Research, Princeton University Press.

Dore, M.H. I. (1993): The Macrodynamics of Business Cycles: A Comparative Evaluation. Blackwell, Oxford.

Dornbusch, R. (1976): Expectations and exchange rate dynamics. Journal of Political Economy, 84, $1161-1175$.

Flaschel, P. and Krolzig, M. (2003): Wage and Price Phillips Curves; An Empirical Analysis of Destabilizing Wage-Price Spirals. Working Paper. Center for Empirical Macroeconomics, Bielefeld University.

Flaschel, P., Gong, G. and Semmler, W. (2001): A Keynesian Macroeconometric Framework for the Analysis of Monetary Policy. Journal of Economic Behaviour and Organization, 46, 101-136.

Gerlach, H.M.S. (1988): World business cycles under fixed and flexible exchange rates. Journal of Money, Credit and Banking, 20, $621-632$.

Greenwood, J. and S.D. Williamson (1989): International financial intermediation and aggregate fluctuations under alternative exchange rate regimes. Journal of Monetary Economics, 23, $401-431$.

Gregory, A. W., Head, A.C. and J. Raynaud (1997): Measuring World Business Cycles. International Economic Review, 38, 677-701.

Guckenheimer, J. and P. Holmes (1983): Nonlinear Oscillations, Dynamical Systems, and Bifurcations of Vector Fields, New York: Springer.

Harding, D. and A. PAgan (2002): Dissecting the Cycle: A Methodological Investigation. Journal of Monetary Economics, 49, 365-381.

Keynes, J.M. (1936): The General Theory of Employment, Interest and Money. New York: Macmillan.

KInD, C (1999): Remarks on the Economic Interpretation of Hopf Bifurcations, Economic Letters, 62, 147-154

Koopman, S.J. and J. Valle E Azevedo (2003): Measuring Synchronisation and Convergence of Business Cycle, Proceedings of the Eurostat Colloquium on Modern Tools for Business Cycle Analysis.

RøDseth, A. (2000): Open Economy Macroeconomics. Cambridge, UK: Cambridge University Press. 
Sargent, T. (1987): Macroeconomic Theory. New York: Academic Press. 